\title{
Positive state mindfulness: \\ A multidimensional model of mindfulness in relation to positive experience
}

\author{
Timothy D. Ritchie - Fred B. Bryant
}

\begin{abstract}
The present research tested Langer's theory of mindfulness in the context of positive experiences: positive state mindfulness. In Study $1\left(N_{1}=586, N_{2}=415\right)$ confirmatory factor analyses indicated that a three-factor model (Focused Attention, Novelty Appreciation, OpenEnded Expectations) fit the data well and explained responses better than a one-factor model. In support of construct validity, Study $2\left(N_{3}=239, N_{4}=126\right)$ suggested that each dimension had a different pattern of associations with unidimensional trait measures of mindfulness, savoring beliefs, trait absorption, uncertainty tolerance, need for structure, and need for cognition. Study $3\left(N_{5}=46\right)$ revealed that each dimension correlated uniquely with the positive affect, self-esteem, interpersonal connectedness, and the overall rehearsal frequency associated with positive autobiographical events. In support of criterion validity in Study 4, in Experiment $1\left(N_{6}=46\right)$ a boredom task decreased Novelty Appreciation, and in Experiment $2\left(N_{7}=92\right)$ a problem-solving task increased Focused Attention. Our data suggest that positive mindfulness is more than the absence of mindlessness and that it includes three distinct dimensions. We discuss the utility of positive mindfulness in both research and practice.
\end{abstract}

Keywords: state mindfulness; positive experience; wellbeing; savoring

\section{Introduction}

Mindfulness is often conceptualized as paying attention flexibly to the present moment. Notwithstanding the different conceptualizations of mindfulness, practitioners and researchers generally agree with the idea that mindfulness involves a present-focused time orientation (Bishop et al., 2004). However, the definitions and applications of mindfulness vary widely, ranging from the philosophy and practices of Buddhism (Chiesa \& Malinowski, 2011), to the clinical sciences and therapies (Kabat-Zinn, 2005; Rothwell, 2006; Teasdale, Segal, Williams, Ridgeway, Soulsby, \& Lau, 2000), to cognitive and emotional research (Brown \& Langer, 1990; Carson \& Langer, 2006; Erisman \& Roemer, 2010), to educational research and interventions (Langer, Hatem, Joss, \& Howell, 1989), social and personality research (Langer, 1997; Langer, Bashner, \& Chanowitz, 1985; Langer \& Moldoveanu, 2000; Sternberg, 2000), and to positive psychology (Brown \& Ryan, 2003; Jacob \& Brinkerhoff, 1999).

A recent definition of mindfulness is:

a process of regulating attention in order to bring a quality of non-elaborative awareness to current experience and a quality of relating to one's experience within an orientation of curiosity, experiential openness, and acceptance... a 
process of gaining insight into the nature of one's mind..." (Bishop et al., 2004, p. 234).

We agree with Bishop et al.'s definition of mindfulness as a process. However, even though an impressive amount of research in recent years has helped to elucidate mindfulness in the clinic, there remains a paucity of evidence that helps to elucidate everyday mindfulness, such as mindfulness that occurs during positive experiences.

In tandem with efforts to clarify the construct of mindfulness in clinical settings, several new measures of mindfulness have emerged, many of them within the past decade. For example, these include the Freiburg Mindfulness Inventory (Buchheld, Grossman, \& Walach, 2001), the Mindful Attention/Awareness Scale (MAAS; Brown \& Ryan, 2003), the MAAS for adolescents (Brown, West, Loverich, \& Biegel, 2011), the modified MAAS (Höfling, Moosbrugger, Schermelleh-Engel, \& Heidenreich, 2011), the Kentucky Inventory of Mindfulness Skills (Baer, Smith, \& Allen, 2004), the Cognitive and Affective Mindfulness ScaleRevised (Feldman, Hayes, Kumar, Greeson, \& Laurenceau, 2007), and the Toronto Mindfulness Scale (Lau et al., 2006), to name a few. These scales have framed mindfulness primarily in terms of Buddhist and clinical conceptualizations of mindfulness, examined mindfulness as a unidimensional trait, and as a hierarchical model (Baer, Smith, Hopkins, Krietemeyer, \& Toney, 2006).

Unique to the present research we grounded our thinking about mindfulness in Langer's social cognitive theory of mindfulness $(1992,1997)$. We appreciate the integrative approaches taken by researchers of mindfulness assessment in the clinic and therapeutic settings; however, in the present research we purposefully narrowed our scope for the sake of testing theorydriven hypotheses about the core characteristics of state mindfulness in the context of pleasant, enjoyable experiences. Next, we acknowledge that Bodner and Langer (2001) proposed and supported the Mindfulness/Mindless Scale (MMS), designed according to Langer's theory. However, they not only examined trait mindfulness, as many other scales have done, but also their data supported a one-factor model. Indeed, recent work by Haigh, Moore, Kashdan, and Fresco (2011) found support for a single-factor model of a brief version of the MMS. The present research extends Langer's theory of mindfulness to positive experiences, and views mindfulness as a state rather than a trait. Additionally, as we detail later, we expected positive state mindfulness to include multiple related but distinct dimensions.

Our approach is consistent with the notion of "everyday mindfulness" suggested by Thompson and Waltz (2007). That we rooted our model in positive experiences reveals that our conceptual basis is essentially consistent with that of clinical psychology. For instance, we garnered support for the idea that pleasant and enjoyable engagement oftentimes includes attention that waxes mindful and, as a state, mindfulness wanes as an experience transpires. Our goal was to capture this empirically, using a variety of statistical and experimental techniques. We do not suggest that all positive experiences necessarily involve mindful states; rather, we suggest that some positive experiences do.

This view is conceptually similar to the mindfulness championed in the clinical literatures, namely, that the presence of maladaptive cognitive, emotional and behavioral patterns suggests the absence of mindfulness. Techniques that build mindfulness skills are desirable. Hence, by extension we believe that individuals who exhibit adaptive cognitive, emotional and behavioral patterns will sometimes evince the presence of mindfulness spontaneously in their everyday positive experiences.

Related to Langer and her colleagues' descriptions of mindfulness (1992, 1997, 2000), in the present research we posited and tested a measurement model of mindfulness in relation to 
positive experience, and emphasize the state-like nature of mindfulness rather than mindfulness as a disposition. Shared among all relevant conceptualizations of mindfulness, we adhere to the idea that mindfulness is a way of paying attention flexibly to what is occurring in the moment and accepting that moment as it is, without judging it, or the self, critically. By focusing on Langer and her colleagues' conceptualization of mindfulness, and by narrowing our focus to positive experiences, the present research fills important conceptual, psychometric and practical gaps in the literature. Additionally, in narrowing our conceptualization of mindfulness to encompass positive state mindfulness, we tend to avoid references to mindlessness. We begin with a brief review of Langer's mindfulness theory, and then later in Study 1 we operationalize each of the dimensions that are derived from this theory.

\section{Review of mindfulness}

Langer's (1992) early conceptualization included mindfulness as a "state of conscious awareness...openness to novelty in which the individual actively constructs categories and distinctions" (p. 289). From this view mindfulness is a somewhat effortful way of attending to the present moment, in contrast to the automatic, shallow processing of mindlessness. Together, both are akin to many dual-process models in social psychology (Chaiken \& Trope, 1999).

In a later conceptualization, Langer and Moldoveanu (2000) revised the definition of mindfulness to emphasize that it is a "process of drawing novel distinctions," such that a perceiver experiences:

a greater sensitivity to one's environment, more openness to new information, the creation of new categories for structuring perception, and enhanced awareness of multiple perspectives in problem solving (Langer \& Moldoveanu, 2000, p. 1).

Consistent with this view, we conceptualized mindfulness in the context of positive experiences as more than merely the absence of mindlessness. In theory, mindfulness may be engaged, sustained, and cultivated by the development and rehearsal of distinct perceptual, cognitive and meta-cognitive skills. On the one hand, these skills may help a person to suppress, inhibit, or eliminate maladaptive habits, heuristics, and automatic thoughts (mindlessness). On the other hand, mindfulness also includes other skills that foster the mobilization, sustainment, and enhancement of adaptive habits, and controlled processing of information. The latter were the primary focus of the present research.

Extending Langer and Moldoveanu's (2000) conception, Sternberg (2000) proposed the following central components of mindfulness:

a) openness to novelty; b) alertness to distinction; c) sensitivity to different contexts; d) implicit, if not explicit, awareness of multiple perspectives; and e) orientation in the present (Sternberg, 2000, p. 12).

Sternberg also emphasized the importance of conceptualizing and measuring mindfulness as a state. His summary of Langer's mindfulness theory, and of the theory's importance to future research, was optimistic:

To the extent that this state [mindfulness] can be measured successfully, such measurement will be a valuable contribution to our understanding of people's interactions with the context in which they live (Sternberg, 2000, p. 18). 
We agree with this conclusion. Hence, the present research attempted to garner support for the idea that state mindfulness is estimable in self-report form, at least indirectly, and can be surmised from positive experiences.

In emphasizing the utility of mindfulness as a psychological construct, Brown and Ryan (2003) suggested that mindfulness is a useful concept, because it "...may be important in disentangling individuals from automatic thoughts, habits, and unhealthy behavior patterns" (Brown \& Ryan, 2003, p. 823). We concur with Brown and Ryan; however, despite their endorsement of mindfulness, our review of the published literature on mindfulness leads us to conclude at present that mindfulness researchers continue to partially agree on how mindfulness should be conceptualized and measured. Such partial agreement has occurred far more in the realm of clinical psychology than in the realm of positive psychology. Furthermore, researchers have not yet tested Langer's mindfulness theory in the context of positive experiences. Hence, the present research is novel in this regard.

Also, while the bulk of the extant public literature on mindfulness suggests that mindfulness is good, in general, such research has mainly framed mindfulness as something lacking; and hence, research is lacking from the view that mindfulness occurs spontaneously, especially during pleasant and enjoyable activities. Therefore, to address these important conceptual, experiential and measurement gaps in the literature, we tested systematically hypotheses that were derived from Langer's social cognitive theory: mindfulness is a state; it is multidimensional; and sometimes occurs spontaneously during positive experiences.

\section{Positive mindfulness}

The notion of mindfulness in everyday experience is at the heart of the concept of savoring, a process through which people regulate and appreciate positive experience (Bryant, 1989, 2003; Bryant \& Veroff, 2007). Savoring involves people's "capacities to attend to, appreciate, and enhance the positive experiences in their lives" (Bryant \& Veroff, 2007, p. 2). Thus, savoring entails a mindfulness of positive thoughts and feelings in relation to either the past (reminiscence), the present (savoring the moment), or the future (anticipation). Further, the capacity to attend to positive experience is a fundamental aspect of savoring. For this reason, in the present research, we purposefully focus on the construct of "positive state mindfulness."

We suggest that positive state mindfulness is central to the notion of savoring the moment. Unless one notices and is mindfully aware of an ongoing positive experience, one cannot savor it. However, just because one is mindfully aware of an ongoing positive experience does not guarantee that one will savor it. Thus, we predict that states of positive mindfulness will be positively related to self-reported savoring capacity, though not so strongly as to be equivalent. Such theorizing is consistent with recent research that established moderate positive correlations between trait mindfulness and positive affect, curiosity, and emotion regulation (Haigh et al., 2011).

Conceptually, it is important to clarify the relationship of temporal orientation to positive mindfulness and savoring, both of which fundamentally entail a present-oriented focus. Just as mindfulness involves a person's attention oriented to the present (Farb et al., 2007), so also is savoring in the moment, in the here and now (Bryant \& Veroff, 2007, p. 8). Yet, it is also possible for people to savor memories from the past or anticipate pleasurable experiences. In such cases, however, people may not necessarily remember past feelings or imagine future feelings, but rather are savoring in the present the way they feel when they think about the past or the future (Bryant \& Veroff, 2007; Ritchie, Skowronski, Hartnett, Wells, \& Walker, 2009; 
Ritchie, Skowronski, Wood, Walker, Vogl, \& Gibbons, 2006). Thus, like mindfulness, savoring always involves some form of conscious present-focused attention on positive experience.

\section{Research hypotheses}

\subsection{The dimensionality of positive mindfulness}

In considering a person's momentary awareness during a positive experience, the question of whether positive state mindfulness is unidimensional or multidimensional arises. Although Langer's theoretical framework highlights multiple conceptual components that should each be present at varying levels when people are being mindful, mindfulness has often been assessed as a unitary phenomenon, in terms of a total score, with no distinction made among different dimensions of mindfulness (Baer et al., 2006; Bodner \& Langer, 2001). Therefore, one purpose of the present research was to test directly the hypothesis that positive mindfulness is multidimensional rather than unidimensional.

\subsection{Construct validation}

A second goal of the present research was to assess the convergent and discriminant validity of dimensions of positive state mindfulness in connection with related state and trait constructs, following validation guidelines proposed by Bryant and colleagues (Bryant, 2000; Bryant et al., 2006). This work involved examining nomological patterns of correlations between our measures of positive mindfulness and measures of other theoretically relevant constructs, including trait mindfulness, perceived savoring capacity, need for cognition, trait absorption, uncertainty tolerance, and need for structure.

In assessing convergent validity, we expected that states of positive mindfulness would be positively correlated with related constructs, such as perceived savoring capacity, trait absorption, and uncertainty tolerance, with which they share common conceptual elements. In assessing discriminant validity, we expected positive mindfulness to be distinct from the need for cognition and need for structure; and, we expected that different dimensions of positive mindfulness would evince different patterns of association with the set of validation criterion measures. Based on our position that positive state mindfulness is distinct from other notions of mindfulness, state and trait mindfulness are different constructs. Mindfulness is not simply the absence of mindlessness. We also expected positive state mindfulness to share relatively little variance with measures of general trait mindlessness.

\section{Study 1}

Guided by Langer's $(1992,1997)$ conceptualizations of mindfulness, we identified the following five theoretical dimensions presumed to underlie states of positive mindfulness: a) Focused Attention, b) Openness to Novelty, c) Novelty Appreciation, d) Categorization and Distinctionmaking, and e) Open-Ended Expectations. The top panel of Figure 1 illustrates this model. To explore the conceptual structure and validity of self-reports related to Langer's theory of mindfulness, we tethered mindfulness items to a pleasant autobiographical event. The present study thus conceptualized mindfulness as a state that, in theory, can be recalled and described as part of an autobiographical episode or experience. Below we briefly describe each hypothesized component of positive mindfulness. 
Figure 1. Conceptualizations of mindfulness
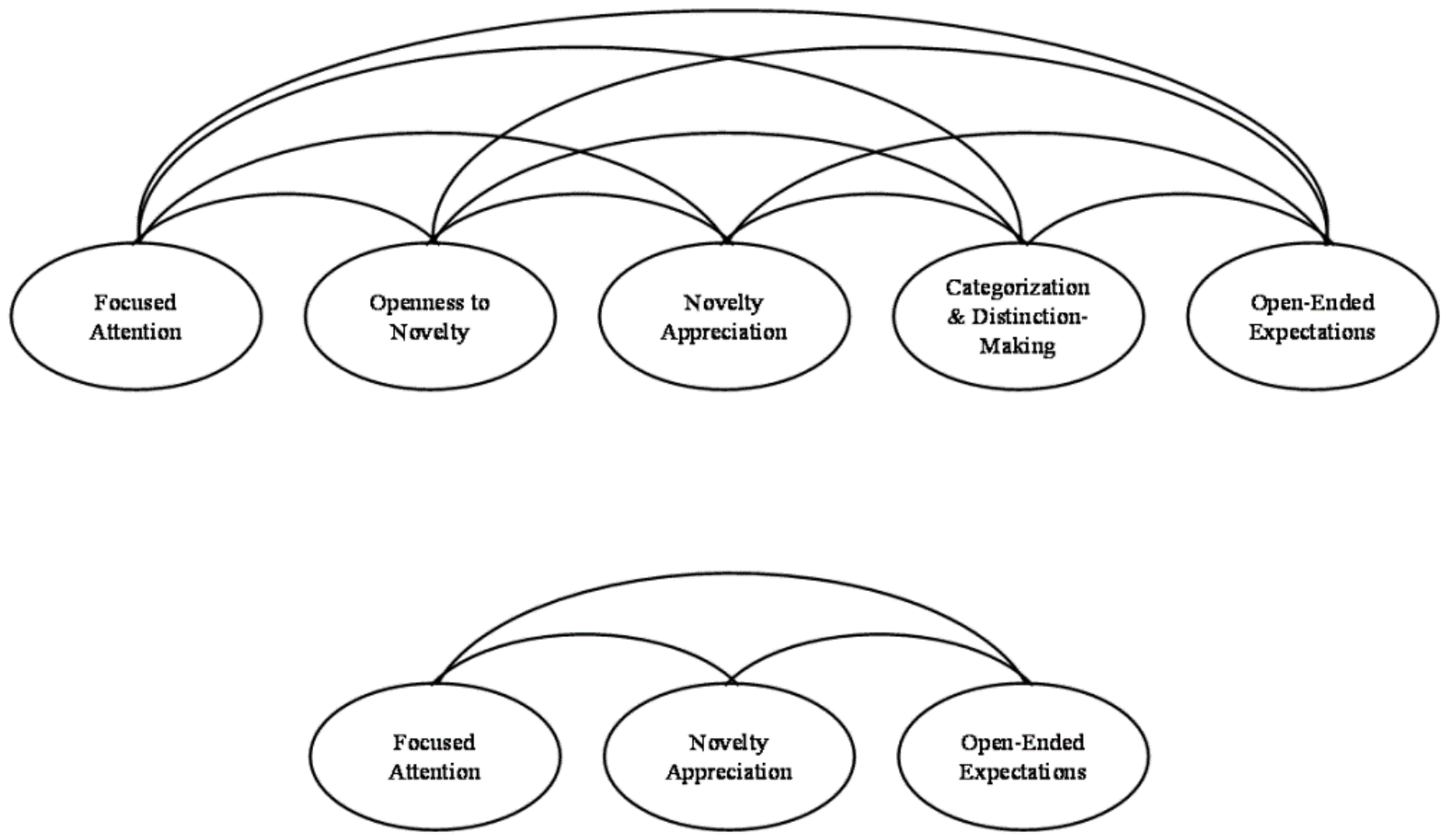

Note: The top panel illustrates the initial model of positive state mindfulness, five correlated factors predicted from Langer's theory; the bottom panel illustrates our refined, three correlated factor model of positive state mindfulness.

\subsection{Method}

\subsubsection{Item construction}

We developed self-report items following procedures recommended by DeVellis (1993). We began by generating an initial list of 37 items, each intended to reflect one of the five characteristics of mindfulness that constitute Langer's theoretical model. All items were prefaced with the phrase: "During my positive experience....". Responses to each item were set to a six-point Likert-type scale $(1=$ strongly disagree, $2=$ disagree, $3=$ disagree somewhat, $4=$ agree somewhat, 5 = agree, and $6=$ strongly agree). ${ }^{1}$ Rather than clustering items and presenting them in their intended conceptual categories, instead we randomly ordered items for administration.

Focused attention. Consistent with Langer's and many others' conceptualization of mindfulness, we hypothesized that focused attention on the present moment is central to mindfulness. Accordingly, we generated a set of items designed to tap the extent to which respondents remembered experiencing a heightened focus of attention to the present moment during a recent positive event. We interpreted Langer and others' descriptions of a person who is mindfully focused as someone whose attention becomes immersed and absorbed in the present moment, akin to but not necessarily the same as, psychological absorption (Tellegen \& Atkinson, 1974; Wild, Kuiken, \& Schopflocher, 1995). A sample item that we created for this dimension is: "...my attention was focused on what was happening just then."

${ }^{1}$ The initial 37 items are available from the first author; see Table 2 for a list of final items and the Appendix for further details. 
Openness to novelty. In theory, mindfulness could be indexed through a person's memory for having been cognitively receptive to novel information. Consistent with this prevailing theoretical notion, we generated a second set of items intended to reflect openness to novelty. The central theme to these items involves being open to learning and being receptive to new ideas. If a person's readiness to perceive novelty reflects mindfulness, then self-reports to such items ought to reflect this component of mindfulness. A sample item for this dimension is: "... I felt open to experience new things."

Novelty appreciation. Another dimension central in many conceptual models of mindfulness is a pleasurable appreciation of perceived novelty. We hypothesized that the state of being receptive to new experiences is distinct from the state of appreciating novelty. Accordingly, we wrote a third set of items intended to reflect the extent to which respondents appreciated a sense of novelty during a recent positive episode. A sample item for this dimension is: "... I enjoyed the newness of the moment." In this item, mindfulness is represented as recalled enjoyment of the novelty that a person perceived during a recent pleasant event. We wrote separate sets of items reflecting openness to and appreciation of novelty because theory suggests both dimensions are related but distinct.

Categorization and distinction-making. When conceptualizing mindfulness, Langer (1992, 1997) referred to a dimension involving distinction-making, categorization, and the creation of new categories to guide perception. To reflect this particular dimension, we wrote nine items that represented perceptions about categorization or about distinction-making. A sample item for this hybrid dimension is: “...I compared different things that were happening". We designed these items to tap the extent to which respondents recalled noticing how they evaluated, appraised, and judged their perceptions during a recent positive experience.

Open-ended expectations. Consistent with Langer and her colleagues' research (Langer \& Moldoveanu, 2000), we generated items intended to reflect a fifth component of mindfulness representing a person's experience of momentary uncertainty and self-reported degree of openended situational expectations. As Langer (1997) stated, "From a mindful perspective... uncertainty creates freedom to discover meaning...if there are meaningful choices, there is uncertainty" (p. 130). To assess this dimension, we constructed four items. A sample item for this dimension is: "...I felt like anything could happen from one moment to the next."

\subsubsection{Participants}

Study 1 included two samples. We used sample 1 to test and refine a measurement model for the set of positive mindfulness items. We split sample 2 in half randomly for use in doubly cross-validating model modifications based on the first sample.

Sample 1 consisted of 586 undergraduate students enrolled in different sections of an Introductory Psychology course at Loyola University Chicago. Reflecting the population of students in this course, the gender composition was 397 females $(68 \%)$, 186 males (32\%), and three respondents who did not indicate their gender $(<1 \%)$. The mean sample age was 19.0 years $(S D=3.0$; mode $=18)$. The ethnic composition was Caucasian $(63 \%)$, Asian $(22 \%)$, Latin $(10 \%)$, Black (4\%), and unspecified (1\%). The final sample consisted of 569 respondents who provided complete data for all 37 items.

Sample 2 consisted of 415 undergraduate students enrolled in different sections of an Introductory Psychology courses at the same university. Prior to analyses, the data were split into two sub-samples-sub-sample 2A $\left(n_{a}=208\right)$ and sub-sample $2 \mathrm{~B}\left(n_{b}=207\right)$-according to random sampling, stratifying on gender. Sub-sample 2A consisted of 162 females $(78 \%)$ and 46 males (22\%). Sub-sample 2B consisted of 161 females $(78 \%), 45$ males $(22 \%)$, and one 
respondent $(<1 \%)$ who did not report gender. Each random sub-sample included a sufficient number of observations for measurement modeling. ${ }^{2}$

\subsubsection{Procedure}

Participants volunteered to complete the research materials in scheduled sessions. They were instructed first to reflect on the past week, and then to describe briefly in writing a positive experience that had occurred during the past week. To permit freedom in selecting positive experiences, we prompted respondents to choose what they deemed to be a positive experience, rather than asking them to report a particular kind of positive experience or asking them to choose from a list of pre-selected events and activities. We intended to elicit relatively ordinary positive experiences rather than momentous, peak experiences. We also wanted to hold constant the recent time frame; hence, we instructed respondents to remember as far back as only one week. After responding to the instrument, participants were debriefed, provided an explanation of the objectives of our study, thanked, and dismissed.

\subsubsection{Analytic strategy}

Using confirmatory factor analysis (CFA). In Study 1, we followed three common analytic strategies used in CFA (Bryant et al., 2006; Jöreskog, 1993). According to Jöreskog (1993), researchers who formulate and then test a single measurement model a priori employ a strictly confirmatory (SC) approach. We used an SC approach to test a priori measurement models using four independent samples. Jöreskog also referred to a second analytic strategy, model generating (MG), in which the researcher posits a tentative initial model, and then uses statistical and theoretical criteria to modify and retest post hoc refinements to improve the model's fit to the data. In the MG scenario, the model to be tested is tentative and not fully established at the outset. Consistent with this approach, we committed one full sample in implementing an MG strategy, adopting both theoretical and empirical criteria in model development. We also adopted a third analytic approach that Jöreskog (1993) termed the alternative models (AM) strategy. Adopting this AM approach in four independent samples, we tested the goodness-of-fit of an alternative one-factor model versus our final multidimensional measurement model of positive mindfulness. ${ }^{3}$

Assessing model fit. We used five different statistical criteria to judge the goodness-of-fit of each CFA model: the goodness-of-fit index (GFI), the non-normed fit index (NNFI), the comparative fit index (CFI), the root mean square error of approximation (RMSEA), and the standardized root mean residual (SRMR). Analogous to $R^{2}$ in multiple regression, GFI reflects the proportion of available variance-covariance information in the data that the given model explains, with larger GFI values representing better model fit. NNFI and CFI indicate how much better the given model fits the data relative to a "null" model, which assumes sampling error alone explains covariation among observed measures (i.e., no common variance exists among measured variables). Bentler and Bonett (1980) recommended that measurement models have GFI, NNCI, and CFI of at least .90. RMSEA reflects the size of the residuals that result when using the model to predict the data, adjusting for model complexity, with smaller values indicating better fit. According to Browne and Cudeck (1993), RMSEA < .05 represents "close

\footnotetext{
2 With this sample, our final nine-item three-factor model included 21 estimated parameters: nine factor loadings, nine unique variances, and three factor correlations. Each random sample thus provided roughly 10 observations per estimated model parameter (na: $\left.208 / 21=9.90 ; n_{b}: 207 / 21=9.86\right)$.

${ }^{3}$ We followed a similar model-testing strategy using exploratory factor analysis with principal axis factor extraction and a promax (oblique) rotation method, and found similar results. They are available upon request from the first author.
} 
fit;" RMSEA between .05 and .08 represents "reasonably close fit;" and RMSEA > .10 represents "an unacceptable model." SRMR reflects the average standardized absolute value of the difference between the elements of the observed covariance matrix and the covariance matrix elements implied by the given model, with smaller values indicating better fit. $\mathrm{Hu}$ and Bentler (1998) suggested that SRMR <.08 represents acceptable model fit. Finally, we used the difference in degrees of freedom and chi-square values (i.e., the likelihood ratio test; Bollen, 1989), to test hypotheses about differences in goodness-of-fit between nested CFA models.

\subsubsection{Hypotheses}

Following the SC strategy, we initially specified a five-factor mindfulness model (Focused Attention, Openness to Novelty, Novelty Appreciation, Categorization and DistinctionMaking, Open-Ended Expectations). However, we acknowledged the possibility that the full five-factor model might be too broad to tap the state mindfulness associated with a recalled positive experience and might need to be reduced to a smaller set of core subscales. We also expected that some items from the initial pool would need to be eliminated because of redundancy or low reliability.

Following the MG strategy, we expected to re-specify the initial measurement model if it achieved inadequate goodness-of-fit, using both theoretical and empirical criteria during model refinement. We hypothesized that our more parsimonious measurement model would fit the data better than both the initial five-factor and alternative one-factor models.

Following the AM strategy, we used data from multiple independent samples to test the hypothesis that the more parsimonious measurement model would again fit the data better than a one-factor model, and would generalize across independent samples. All of the structural analyses in Study 1 were aimed at developing and confirming a theory-grounded measurement model, whose construct validity would be assessed in Study 2.

\subsection{Results and discussion}

\subsubsection{Strictly confirmatory: Testing the a priori measurement model}

Initial screening of the pool of items suggested they were reasonably normally distributed. To test the first hypothesis, we subjected the initial 37-item, oblique five-factor model to maximum-likelihood CFA using LISREL 8.54 (Jöreskog \& Sörbom, 1996) to analyze the covariance matrix. Not surprisingly, we found that the initial full model fit the data unsatisfactorily, $\chi^{2}(619, N=569)=2551.03, \mathrm{GFI}=.77, \mathrm{NNFI}=.71, \mathrm{CFI}=.73$, RMSEA $=.08$, SRMR $=.08$ (see Table 1). Thus, the data did not confirm the a priori five-factor model for the initial pool of 37 items. Accordingly, we adopted the MG strategy and tested a series of modified measurement models for the purpose of model refinement.

\subsubsection{Model generating: Refining the initial factor structure}

We used established measurement modeling procedures (Bryant, King, \& Smart, 2006) to refine this initial model by iteratively eliminating items with squared multiple correlations $<.30$ and combining factors that were highly inter-correlated (i.e., $r>90$ ), while simultaneously requiring factors to have acceptable reliabilities (i.e., Cronbach's $\alpha \geq .70$ ). This approach yielded: a) first, a five-factor model for 20 items that fit the data better but not acceptably; $b$ ) then, a three-factor model for 20 items that still fell short of acceptable fit; and, c) eventually a three-factor model for 9 items that fit the data well (see Table 1). The final refined model consisted of three factors - Novelty Appreciation, Focused Attention, and Open-Ended Expectations - each with 
Table 1. Results from confirmatory factor analyses of the positive state mindfulness measurement models

\begin{tabular}{ccccccccccc}
\hline \hline Strategy & Model & $N$ & $\#$ items & $\chi^{2}$ & $d f$ & GFI & NNFI & CFI & RMSEA & SRMR \\
\hline SC & 5-factor & 569 & 37 & 2551.03 & 619 & .77 & .71 & .73 & .084 & .081 \\
MG & 5-factor & 569 & 20 & 803.63 & 160 & .87 & .79 & .82 & .088 & .068 \\
MG & 3-factor & 569 & 20 & 864.89 & 167 & .86 & .78 & .81 & .089 & .071 \\
MG $^{\text {a }}$ & 3-factor & 569 & 9 & 103.82 & 24 & .96 & .91 & .94 & .076 & .059 \\
$\mathrm{AM}^{\mathrm{a}}$ & 1-factor & 569 & 9 & 534.62 & 27 & .81 & .50 & .62 & .193 & .115 \\
$\mathrm{SC}^{\mathrm{a}}$ & 3-factor & 208 & 9 & 74.48 & 24 & .93 & .90 & .93 & .097 & .062 \\
$\mathrm{SC}^{\mathrm{a}}$ & 3-factor & 207 & 9 & 71.52 & 24 & .93 & .87 & .91 & .095 & .066 \\
$\mathrm{SC}^{\mathrm{a}}$ & 3-factor & 415 & 9 & 114.87 & 24 & .94 & .91 & .93 & .095 & .060 \\
$\mathrm{AM}$ & 1-factor & 415 & 9 & 397.58 & 27 & .80 & .68 & .70 & .199 & .109 \\
$\mathrm{SC}$ & 3-factor & 239 & 9 & 101.10 & 24 & .91 & .87 & .90 & .116 & .071 \\
$\mathrm{AM}$ & 1-factor & 239 & 9 & 318.76 & 27 & .76 & .60 & .61 & .220 & .134 \\
$\mathrm{SC}$ & 3-factor & 1361 & 9 & 252.91 & 24 & .96 & .93 & .94 & .085 & .052 \\
$\mathrm{AM}$ & 1-factor & 1361 & 9 & 1215.13 & 27 & .81 & .67 & .67 & .194 & .109 \\
\hline \hline
\end{tabular}

a Our refined final model.

Note $. \mathrm{SC}=$ Strictly Confirmatory analysis, $\mathrm{MG}=$ Model Generating analysis, $\mathrm{AM}=$ Alternative Models analysis. GFI $=$ Goodness of Fit Index. NNFI $=$ Non-Normed Fit Index. CFI $=$ Comparative Fit Index. RMSEA = Root Mean Square Error of Approximation. SRMR = Standardized Root Mean Square Residual. Results obtained using LISREL 8.54 (Jöreskog \& Sörbom, 1996).

three items. The bottom panel of Figure 1 illustrates this model. The resulting measurement model provided an acceptable goodness-of-fit to the data: $\chi^{2}(24, N=569)=103.82$, GFI $=.96$, $\mathrm{NNFI}=.91, \mathrm{CFI}=.94, \mathrm{RMSEA}=.08, \mathrm{SRMR}=.06$.

\subsubsection{Testing alternative models: Is positive mindfulness multidimensional?}

We next tested whether this multidimensional model explained responses to the nine items better than a unidimensional model. As hypothesized, a one-factor model provided a poor fit to the data: $\chi^{2}(27, N=569)=534.62, \mathrm{GFI}=.81, \mathrm{NNFI}=.50, \mathrm{CFI}=.62, \mathrm{RMSEA}=.19$, SRMR $=.11$. Thus, the three-factor model fit the data better than a one-factor model, $\Delta \chi^{2}(3, N=569)=430.80$, $p<.0001$. These results indicate that positive mindfulness is multidimensional and reflects at least three basic dimensions.

\subsubsection{Strictly confirmatory: Testing the cross-sample generalizability of the refined model}

The next set of analyses assessed how well the goodness-of-fit of the nine-item three-factor model replicated across two independent samples $(N s=207$ and 208). We ran identical analyses for each independent sample, and for the pooled data from both samples combined $(N=415)$. Results revealed that the refined three-factor model fit the data of each independent sample adequately: $\chi^{2}(24, N=207)=74.48, \mathrm{GFI}=.93, \mathrm{NNFI}=.90, \mathrm{CFI}=.93, \mathrm{RMSEA}=.09$, SRMR $=.06$; and, $\chi^{2}(24, N=208)=71.52, \mathrm{GFI}=.93, \mathrm{NNFI}=.87, \mathrm{CFI}=.91$, RMSEA $=.09$, SRMR $=.06$, respectively.

Assessing the cross-sample generalizability of the refined three-factor model, additional tests of factorial invariance using multi-group CFA (Jöreskog \& Sörbom, 1996) revealed that the factor loadings, factor variances-covariances, and unique variances of the three-factor model were equivalent for the two independent samples, $\chi^{2}(21, N=415)=30.83, p<.08$. In addition, 
the three-factor model provided an acceptable goodness-of-fit to the data of the two independent samples combined, $\chi^{2}(24, N=415)=114.87$, GFI $=.94$, NNFI $=.91, \mathrm{CFI}=.92$, RMSEA $=.09$, SRMR $=.06$ (see Table 1 ). These findings strongly confirm the cross-sample generalizability of the three-factor CFA model.

\subsubsection{Testing alternative models}

In contrast, a unidimensional one-factor model fit the pooled data relatively poorly: $\chi^{2}(27, N=$ $415)=397.58, \mathrm{GFI}=.80, \mathrm{NNFI}=.68, \mathrm{CFI}=.70, \mathrm{RMSEA}=.20, \mathrm{SRMR}=.10$, and provided a significantly worse fit compared to the three-factor model, $\Delta \chi^{2}(3, N=415)=282.71, p<$ .0001. Thus, the data suggest that the intended three-factor measurement model provides a reasonable representation of state mindfulness in relation to positive experience. This refined three-factor model incorporates the a priori mindfulness dimensions of Novelty Appreciation, Focused Attention, and Open-Ended Expectations as originally hypothesized. However, the refined three-factor model excludes the initial mindfulness dimensions of Categorization and Distinction-Making and Openness to Novelty. Table 2 displays the completely standardized factor loadings from the confirmatory factor analyses. Table 3 displays descriptive statistics and reliability estimates for the refined model.

Table 2. CFA factor loadings for the nine-item, three-factor positive state mindfulness model

\begin{tabular}{|c|c|c|c|c|c|}
\hline \multirow[b]{2}{*}{ Factor } & \multirow[b]{2}{*}{ Items } & \multicolumn{4}{|c|}{ Sample } \\
\hline & & 1 & 2 & 3 & 4 \\
\hline \multirow[t]{3}{*}{ Focused Attention } & $\begin{array}{l}\text { My attention was focused on what } \\
\text { was happening just then. }\end{array}$ & .67 & .65 & .64 & .66 \\
\hline & $\begin{array}{l}\text { My attention was absorbed in the } \\
\text { moment. }\end{array}$ & .78 & .73 & .70 & .84 \\
\hline & $\begin{array}{l}\text { I was aware of nothing else except } \\
\text { what I was going through right } \\
\text { then. }\end{array}$ & .65 & .62 & .69 & .72 \\
\hline \multirow[t]{3}{*}{ Novelty Appreciation } & $\begin{array}{l}\text { I enjoyed the newness of the } \\
\text { moment. }\end{array}$ & .68 & .71 & .78 & .62 \\
\hline & $\begin{array}{l}\text { I took great pleasure in } \\
\text { experiencing new things. }\end{array}$ & .75 & .80 & .76 & .79 \\
\hline & $\begin{array}{l}\text { Everything happening seemed } \\
\text { unique to me. }\end{array}$ & .63 & .62 & .57 & .73 \\
\hline \multirow[t]{3}{*}{ Open-Ended Expectations } & I wasn't sure of what to expect. & .74 & .77 & .75 & .72 \\
\hline & $\begin{array}{l}\text { I couldn't tell how things were } \\
\text { going to unfold. }\end{array}$ & .79 & .80 & .77 & .82 \\
\hline & $\begin{array}{l}\text { I felt like anything could happen } \\
\text { from one moment to the next. }\end{array}$ & .64 & .70 & .58 & .66 \\
\hline
\end{tabular}

Note: CFA = confirmatory factor analysis. Tabled above are completely standardized factor loadings from maximum-likelihood CFA via LISREL 8.54 (Jöreskog \& Sörbom, 1996). Sample 1: pooled $N=1361$. Sample 2: $N=569$. Sample 3: $N=415$. Sample 4: $N=239$. One smaller sample $(n=126)$ was not separately subjected to confirmatory factor analysis (CFA) but was included in the pooled Sample 1. 
Table 3. Descriptive Statistics for the Positive State Mindfulness Scales

\begin{tabular}{ccccccc}
\hline Sub-scale & $N$ & $\alpha^{\text {a }}$ & Mean & SD & Min. & Max. \\
\hline Focused Attention & & & & & & \\
(3 items) & 583 & .71 & 4.75 & 0.98 & 1.00 & 6.00 \\
& 415 & .73 & 4.84 & 0.99 & 1.00 & 6.00 \\
& 239 & .77 & 4.97 & 0.88 & 2.00 & 6.00 \\
& 126 & .79 & 4.76 & 1.04 & 1.00 & 6.00 \\
Novelty Appreciation & 1363 & .73 & 4.82 & 0.97 & 1.00 & 6.00 \\
(3 items) & & & & & & \\
& 582 & .73 & 4.60 & 1.02 & 1.00 & 6.00 \\
& 415 & .70 & 4.41 & 1.07 & 1.00 & 6.00 \\
& 239 & .75 & 4.51 & 1.10 & 1.33 & 6.00 \\
Open-Ended Expectations & 126 & .74 & 4.32 & 1.11 & 1.00 & 6.00 \\
(3 items) & 1362 & .72 & 4.50 & 1.06 & 1.00 & 6.00 \\
& & & & & & \\
& 585 & .73 & 3.78 & 1.20 & 1.00 & 6.00 \\
& 415 & .80 & 3.77 & 1.28 & 1.00 & 6.00 \\
& 239 & .77 & 3.78 & 1.28 & 1.00 & 6.00 \\
& 126 & .76 & 3.87 & 1.27 & 1.00 & 6.00 \\
& 1365 & .76 & 3.78 & 1.24 & 1.00 & 6.00 \\
\hline \hline
\end{tabular}

a Cronbach's alpha, an index of item internal consistency.

Additionally, to ascertain the unique proportion of variance explained by a second-order factor and unique variance explained by each of the three first-order factors $(N=415)$, a SchmidLeiman solution was examined to assess the proportion of variance explained by a higher-order factor compared to the proportion of variance explained by each of the three hypothesized factors. Results from Wolff and Preising's (2005) macro for SAS, version 9.1 suggest that the second-order factor (i.e., recalled positive mindfulness) accounted for only $19.4 \%$ of the variance and the three factors jointly accounted for $80.6 \%$ (Focused Attention $=34 \%$, Novelty Appreciation $=26.4 \%$, and Open-Ended Expectations $=20.2 \%$ ). These results converge with the previous findings that suggest a multidimensional model is a better fit with the data than a unidimensional or higher-order factor model.

\subsubsection{Correlations among dimensions of mindfulness}

Finally, we used equality constraints via CFA (Bryant et al., 2006) to directly compare correlations among the three dimensions, using the data of the pooled independent samples ( $N$ $=415$ ). These analyses revealed that: a) Focused Attention was equally correlated with Novelty Appreciation $(r=.61)$ and Open-Ended Expectations $\left.(r=.67), \Delta \chi^{2}(1)=0.70, p<.41 ; \mathrm{b}\right)$ Novelty Appreciation was more correlated with Focused Attention $(r=.61)$ than it was with OpenEnded Expectations $(r=.36), \Delta \chi^{2}(1)=17.10, p<.0001$; and, c) Open-Ended Expectations had more to do with Focused Attention $(r=.67)$ than with Novelty Appreciation $(r=.36), \Delta \chi^{2}(1)=$ 26.05, $p<.0001$. These results lend initial support to the divergent validity of the three dimensions that compose our refined measurement model. 


\section{Study 2}

In Study 1 we developed and confirmed a multidimensional factor model of recalled state mindfulness during a recent pleasant experience, and we established its structural validity using confirmatory factor analytic techniques. In Study 2, we collected and analyzed two additional data sets for the purpose of testing the construct validity of each of the three mindfulness components with existing constructs.

The goal of the second study was to investigate further our refined nine-item three-factor model of positive mindfulness, and extend our construct validation efforts to include more systematic tests of the model's convergent, discriminant, and nomological validity. Toward this goal, we widened the conceptual net by administering the refined positive mindfulness measurement instrument along with a) existing measures of trait mindfulness, b) scales conceptually related to mindfulness, and c) scales conceptually distinct from mindfulness.

Thus, in addition to administering our refined three-factor measure, we administered two other self-report measures of mindfulness: the dispositional Mindfulness/Mindlessness Scale (Bodner \& Langer, 2001), and the dispositional Mindful Attention/Awareness Scale (Brown \& Ryan, 2003). Here, we sought to identify points of conceptual convergence and divergence between our state measure of positive mindfulness and trait measures of general mindfulness. In addition, we assessed five other constructs: a) savoring beliefs assessed in terms of the perceived capacity to savor positive experiences through anticipation, through appreciating the moment, and through reminiscence; b) trait absorption; c) need for cognition; d) uncertainty tolerance; and, e) personal need for structure.

As a global test of discriminant validity, we hypothesized that each of the three dimensions of positive mindfulness would show a different pattern of associations with the set of criterion measures. As a global test of convergent validity, we hypothesized that trait absorption would be positively related to all three dimensions of positive mindfulness and that the need for structure would be negatively correlated with all three dimensions of positive mindfulness. We hypothesized that: a) all three temporal forms of savoring beliefs would be positively related to the mindful appreciation of novelty and to positive focused attention, but less strongly related to open-ended expectations; $b$ ) the capacity to savor positive experiences prospectively through anticipation would be negatively related to open-ended expectations; and c) tolerance of uncertainty would be positively related to the appreciation of novelty and open-ended expectations, but less strongly related to positive temporal focus. Below we provide more specific theoretical foundations for our hypotheses concerning each of these criterion measures.

\subsection{Method}

\subsubsection{Participants and procedure}

Sample $3(N=239)$ included 165 females $(69 \%)$ and 74 males $(31 \%)$ with one respondent who did not report gender $(<1 \%)$. Sample $4(N=126)$ included 54 women $(42.9 \%), 33$ men $(26.2 \%)$, and 39 respondents $(31 \%)$ for whom gender information was not collected. The survey administration procedure used in Study 2 was essentially the same as the procedure described in Study 1. The only change was that respondents in Study 2 needed more time to complete the additional validation measures we administered. To counteract any order effects, three different item orders were arranged and then randomly assigned to respondents. As noted below, not all instruments were administered to all respondents. 


\subsubsection{Measures}

MMS. We measured dispositional mindfulness, or the stable trait of proneness to mindfulness in Samples 3 and 4, using Bodner and Langer's (2001) Mindfulness/Mindlessness Scale (MMS). The MMS consists of 21 items, each assessed by a 7-point scale $(1=$ strongly disagree, $7=$ strongly agree, with middle point $=$ neutral). The MMS composite score was reliable (Sample 3 Cronbach's $\alpha=.80$, Sample 4 Cronbach's $\alpha=.87$ ). Bodner and Langer (2001) presented evidence suggesting that their scale taps into a person's self-reported characteristic propensity to be mindful. Even though the MMS is a trait measure and our instrument is a state measure, both measures are based on Langer's conceptualization of mindfulness. Therefore, we hypothesized positive correlations between the MMS and at least one of our scales.

MAAS. In Sample 4, we also measured dispositional mindfulness using the Mindful Attention/Awareness Scale (MAAS; Brown \& Ryan, 2003), a 15-item unidimensional measure of trait mindfulness, with items assessed using a 6-point scale $(1=$ almost always to $6=$ almost never). The MAAS is worded such that higher total scores suggest the absence of mindlessness in respondents' lives (Sample 4 Cronbach's $\alpha=.88$ ). Given that the MAAS items were only indirectly based on Langer's conceptualization of mindfulness, and that the items tapped into the absence of mindlessness rather than the presence of mindfulness, we expected that the total score of this trait measure would not correlate positively with our three scales.

SBI. Both Samples 3 and 4 completed the Savoring Beliefs Inventory (SBI; Bryant, 2003), a self-report measure assessing a person's perceived ability to enjoy positive events by: a) Anticipating the Future (Sample 3 Cronbach's $\alpha=.72$, Sample 4 Cronbach's $\alpha=.81$ ); b) Savoring the Moment (Sample 3 Cronbach's $\alpha=.72$, Sample 4 Cronbach's $\alpha=.81$ ); and, c) Reminiscing about the Past (Sample 3 Cronbach's $\alpha=.83$, Sample 4 Cronbach's $\alpha=.81$ ). Each scale has 8 items (4 positively-worded, 4 negatively-worded) assessed using a 7-point scale $(1=$ strongly disagree to 7 = strongly agree). Given that savoring involves mindfulness of positive stimuli, we expected that our present-oriented Focused Attention subscale would correlate positively with the present-oriented Savoring the Moment subscale of the SBI. We also expected that Novelty Appreciation would positively correlate with Savoring the Moment. Based on the notion that anticipation requires a fixed positive expectation regarding the future, we expected that savoring through Anticipation would correlate negatively with the positive mindfulness dimension of Open-Ended Expectations.

TAS. We assessed trait absorption in Sample 4 using Tellegen's Absorption Scale (TAS; Tellegen \& Atkinson, 1974), consisting of 34 items (Sample 4 Cronbach's $\alpha=.79$ ) assessed by a 7 -point Likert scale $(0=$ never to $7=$ always $)$. Although trait absorption has primarily been linked to hypnotic susceptibility, absorption is also associated with experiential involvement (Wild et al., 1995). Thus, we expected that our Focused Attention scale would correlate positively with the TAS, because both measures are present-time oriented and suggest sensory-perceptual and experiential engagement.

UTS. We assessed individual differences in the capacity to tolerate situational uncertainty in Sample 4 using the Uncertainty Tolerance Scale (UTS; Dalbert, 1999), an 8-item measure of the extent to which a person tolerates spontaneity, surprise, and disrupted routines. The UTS contains both present- and future-focused items and uses a 6-point scale $(1=$ strongly disagree to $6=$ strongly agree). The version we used was translated by C. Dalbert from German into English (using back-translation). UTS total score is used in our analyses (Sample 4 Cronbach's $\alpha=.62$ ). Although this reliability coefficient is somewhat low, we expected that UTS total score would correlate positively with each of our subscales. 
PNS. We measured individual differences in the need for routine and structure in Sample 4 using the Personal Need for Structure Scale (PNS; Neuberg \& Newsome, 1993), consisting of 12 items each assessed by a 6-point scale $(1=$ strongly disagree to $6=$ strongly agree $)$. A higher PNS total score suggests a greater need for simple structure in life (Sample 4 Cronbach's $\alpha=.81$ ). Because people less inclined to be spontaneous are likely to approach positive experiences with fixed plans and clear-cut future expectations, we would expect them to report lower levels of present-focused attention, appreciation of novelty, and open-ended expectations. From this view, individuals' personal need for structure, in theory, should correlate negatively with all three of our components of mindfulness.

NFC. Finally, we measured individual differences in the motivation to think and understand in Sample 4 using the 18-item version of the Need for Cognition scale (NFC; Cacioppo \& Petty, 1982), with each item assessed using a 5-point scale $(1=$ extremely uncharacteristic to $5=$ extremely characteristic). In Sample 4, Cronbach's $\alpha$ for NFC was .87. We hypothesized that NFC has little to do with mindfulness in relation to positive situations, and hence would be uncorrelated with our subscales.

\subsection{Results and discussion}

We first computed unit-weighted average scores for each of our three subscales, along with scale and subscale scores for each of the criterion measures. We next used meta-analytic statistical methods to organize and simplify construct validation across the two samples. When the same constructs were assessed in both Sample 3 and 4, we calculated and reported an average $r$ weighted by sample size (D-Stat 1.11; Johnson, 1995). When a bivariate correlation was assessed in only one sample, we reported the Pearson product-moment correlation. Table 4 displays the correlations observed among our positive mindfulness subscales, the measures of trait mindfulness, and each of the criterion measures in Study 2.

Table 4. Meta-analytic and bivariate correlations among positive state mindfulness scales, trait mindfulness scales and related constructs

\begin{tabular}{ccccccc}
\hline \hline Measures & $N$ & $\begin{array}{c}\text { Focused } \\
\text { Attention }\end{array}$ & $\begin{array}{c}\text { Novelty } \\
\text { Appreciation }\end{array}$ & $\begin{array}{c}\text { Open-Ended } \\
\text { Expectations }\end{array}$ & MMS & MAAS \\
\hline MMS & $365^{\mathrm{a}}$ & .07 & $.32^{* *}$ & $.15^{*}$ & -- & -- \\
MAAS & 126 & .04 & .13 & $-.32^{* *}$ & $.25^{* *}$ & -- \\
SBI Anticipation & $365^{\mathrm{a}}$ & $.30^{* *}$ & $.28^{* *}$ & -.11 & $.32^{* *}$ & $.30^{*}$ \\
SBI Savor the Moment & $365^{\mathrm{a}}$ & $.41^{* *}$ & $.27^{* *}$ & -.08 & $.34^{* *}$ & $.46^{* *}$ \\
SBI Reminiscence & $365^{\mathrm{a}}$ & $.21^{* *}$ & $.17^{*}$ & $-.19^{* *}$ & $.35^{* *}$ & $.49^{* *}$ \\
TAS & 126 & $.17^{*}$ & .15 & $.18^{*}$ & $.30^{* *}$ & $-.29^{* *}$ \\
UTS & 126 & $.25^{* *}$ & $.20^{*}$ & .16 & $.36^{* *}$ & .02 \\
PNS & 126 & $-.19^{*}$ & -.14 & -.10 & $-.31^{* *}$ & $-.18^{*}$ \\
NFC & 126 & .07 & -.06 & -.08 & $.61^{* *}$ & $.26^{* *}$ \\
\hline \hline
\end{tabular}

${ }^{*} p<.05 .{ }^{* *} p<.01$. ${ }^{a}$ Meta-analytic correlations.

Note: MMS = Mindfulness/Mindlessness Scale (Bodner \& Langer, 2001). MAAS = Mindful Attention/Awareness Scale (Brown \& Ryan, 2003), higher scores reflect lower trait mindlessness. SBI = Savoring Beliefs Inventory (Bryant, 2003). TAS = Tellegen's Absorption Scale (Tellegen \& Atkinson, 1974). UTS = Uncertainty Tolerance Scale (Dalbert, 1999). PNS = Personal Need for Structure (Neuberg \& Newsome, 1993). NFC = Need for Cognition (Cacioppo \& Petty, 1982). 
In general, the validation results support the construct validity of our measure of mindfulness in relation to positive experience. Confirming hypotheses, each of our three subscales of positive mindfulness demonstrated a different pattern of correlations with the criterion measures. These results support the discriminant validity of the three positive mindfulness subscales. Below we consider the specific relations of each criterion measure with our subscales of positive mindfulness.

\subsubsection{Trait mindfulness/mindlessness}

As predicted, the data suggest that our positive state mindfulness subscales were more similar to the MMS than to the MAAS; both of the latter are trait measures of mindfulness. Supporting our hypotheses, Novelty Appreciation and Open-Ended Expectations each evidenced modest positive correlations with the MMS. Our items were based entirely on Langer's conceptualization of mindfulness, which has consistently included the notions of seeking and producing novelty (i.e., novelty appreciation) and a tolerance for uncertainty (i.e., open-ended situational expectations).

Unexpectedly, our Open-Ended Expectations subscale correlated negatively with the MAAS. What is it about being mindless that might actually predispose people to have more openended expectations in positive situations? We speculate that people who are characteristically unaware of their surroundings tend to lack expectations about what will happen next in positive situations; that is, characteristically mindless individuals are typically unsure about what to expect, cannot tell how things are going to unfold, and feel like anything could happen from one moment to the next (i.e., the three items comprising our Open-Ended Expectations subscale). Although this clearly seems to be the case, it leads to the paradoxical conclusion that being characteristically mindless actually helps people avoid closed-ended expectations during positive experiences; being mindless, in general, predisposes a person to be mindful with respect to remaining open to unlimited possibilities in positive situations. This ironic interpretation not only supports the discriminant validity of our Open-Ended Expectations subscale, but also illustrates an important way in which mindfulness is not simply the opposite of mindlessness. Moreover, that trait mindlessness is associated with positive state mindfulness, specifically concerning open-ended expectations, demonstrates the importance of distinguishing general trait mindlessness from mindfulness in relation to positive situations.

\subsubsection{Savoring beliefs}

Concerning the criterion measures of savoring beliefs, the data confirmed the hypothesized pattern of correlations. Specifically, as hypothesized our Focused Attention and Novelty Appreciation subscales were positively correlated with the perceived capacity to savor positive experiences through anticipation, savoring the moment, and reminiscence (see Table 4). Also as predicted, Open-Ended Expectations correlated negatively with Anticipation, although this effect did not reach statistical significance. Contrary to predictions, however, Open-Ended Expectations correlated negatively with savoring through reminiscence $(r=-.19, p<.01)$. This latter finding suggests that being better at savoring retrospectively predisposes people to be more certain about what to expect, how things will unfold, and what will happen from one moment to the next in ongoing positive situations. Given that stronger savoring beliefs via reminiscence are associated with more active memory-building during unfolding positive experiences (Bryant \& Veroff, 2007), the tendency to savor through reminiscence may predispose people to be more closed-ended with respect to expectations in positive situations, so as to facilitate memory encoding for later recall. 


\subsubsection{Absorption}

Further supporting our a priori hypotheses, the measure of trait absorption (TAS) correlated positively with two out of three of our subscales: Focused Attention and Open-Ended Expectations (see Table 4). These results suggest that individuals with a tendency to become absorbed in the moment also tended to report being mindful during a recent positive event.

\subsubsection{Uncertainty tolerance}

Also consistent with our hypotheses, Uncertainty Tolerance correlated positively with each of our subscales, though only two of these correlations (Focused Attention and Novelty Appreciation) were statistically significant. Individuals with a proclivity to respond favorably to surprise and who tolerate disruption in daily routines tend to report being mindful during a recent positive experience.

\subsubsection{Need for structure}

Further supporting our hypotheses, Personal Need for Structure correlated negatively with our subscales, though only one of these negative correlations, Focused Attention $(r=-.19, p<.05)$, was statistically significant. Thus, the more need for structure, the less reported Focused Attention during recent positive experiences. Alternatively, the less strongly individuals endorsed a personal need for structure, the more strongly they reported attending to the present during a recent positive experience.

\subsubsection{Need for cognition}

Finally, supporting the discriminant validity of positive mindfulness, as hypothesized all three of our scales were uncorrelated with need for cognition $\left(\left|r_{\mathrm{s}}\right|<.09, n s\right)$. The lack of a relation between NFC and state mindfulness suggests that the need for mental activity and mindfulness during positive activity are conceptually distinct. Notice, in contrast, that both of the trait measures of mindfulness - the MAAS $(r=.26, p<.01)$ and MMS $(r=.61, p<.01)$-were correlated positively with need for cognition (see Table 4). These results provide further evidence of the discriminant validity of positive state mindfulness, as distinct from trait mindfulness/mindlessness.

\section{Study 3}

In Study 1 we developed and confirmed a multidimensional factor model of state mindfulness during a recent pleasant experience, and we established its structural validity using confirmatory factor analytic techniques. In Study 2, we collected and analyzed two additional data sets that garnered evidence of the construct validity of each of the three mindfulness components with existing constructs. The goal of Study 3 was to investigate further our refined nine-item, three-factor model of positive mindfulness, and extend our construct validation efforts to include more tests of the model's convergent, discriminant, and nomological validity.

Toward this goal, we widened the conceptual net by again administering the refined positive mindfulness scale along with scales that would help distinguish our three sub-scales from each other. We were concerned with the unique pattern of correlations between positive mindfulness and conceptually related pleasant memorial phenomena, such as a) nostalgia, b) a sense of purpose in life, c) self-esteem, d) self-continuity, and e) interpersonal connectedness. Research has established a solid link between nostalgia and subjective wellbeing (Hepper, Ritchie, Sedikides, \& Wildschut, 2012; Wildschut, Sedikides, Arndt, \& Routledge, 2006). As our 
notion of positive mindfulness is itself grounded in subjective wellbeing, we anticipated that our scales would correlate positively with nostalgia and its correlates. Additionally, we included items that assessed common features of positive events in memory, such as overall event rehearsal frequency, affect pleasantness at an event's occurrence, and affect pleasantness at event recall (Ritchie et al., 2006; Ritchie et al., 2009; Walker, Skowronski, Gibbons, Vogl, \& Ritchie, 2009).

We were concerned with if, and the extent to which, our positive mindfulness scales correlated uniquely with event-related affect, such as the perceived affect felt at a positive event's occurrence and the affect prompted by thinking about the event at recall. We reasoned that Novelty Appreciation, for example, could correlate more strongly with affect at recall than with affect at occurrence, in part because the pleasant affect could be used to broaden and build upon a person's current skills that could be useful for emotion-regulation (Frederickson, Cohn, Coffey, Pek, \& Finkel, 2008). Finally, in relation to positive events, we wondered if people would report thinking about some aspects of mindfulness more often than others; hence, we examined the extent to which rehearsal frequency correlates positively with each dimension of positive mindfulness.

\subsection{Method}

\subsubsection{Participants}

Participants were undergraduate students $(N=46)$ from the University of Limerick; half were women, half were men. Their average age was 21.8 years $(S D=5.82)$. Over $90 \%$ were Irish.

\subsubsection{Procedure}

Research Assistants contacted students via email using class rosters. Volunteers were emailed an informed consent form, the instructions and a spreadsheet file, in which they entered their autobiographical events and event ratings. Participants were prompted to recall and type a brief description of two positive autobiographical events: "Please recall a moment from your life that felt pleasant to you at the time." Following this, they were prompted to simply describe "What happened?" in a text space in the spreadsheet. They dated each of their events by indicating how old they were at the time the event occurred. Event age was computed by subtracting their ages at each event from their current age. Next, each returned their completed file to the research assistant, who then emailed each participant a debrief form, thanked them for participation and offered to deliver them a small token of appreciation for their contributions to the study.

\subsubsection{Measures}

Participants rated both of their positive events using a number of scales that have been used to study autobiographical event characteristics (Ritchie et al., 2006) and the functions of nostalgia (Wildschut et al., 2006). Each of the items that follow was prefaced with "Thinking about this event..." on which participants rated both of their events along 6-point Likert scales (strongly disagree $=1$ to 6 = strongly agree), following the general instruction, "please indicate your agreement or disagreement by typing a number next to each statement."

The sample sizes reported below are the event sample sizes, not the person sample sizes; hence, the partial correlations preserve the multi-level data structure. Such sizes vary due to skipped responses on some items for some events per person. The mean of each item 
characteristic was used in the analysis. Higher ratings reflect strong agreement that the items characterize what it was like for participants to think about a positive event.

\subsubsection{Positive mindfulness scales}

Focused Attention was assessed with two items: "focuses my attention on what is happening right now" and "absorbs my attention in the moment." Responses to these items were uncorrelated, $r(91)=.13, p=.21$. Novelty Appreciation was assessed with two items: "makes me enjoy the newness of this moment" and "reminds me to take pleasure in experiencing new things." Responses to these items correlated positively, $r(90)=.38, p<.0005$. Open-Ended Expectations was assessed with two items: "makes me unsure of what to expect" and "reminds me that I cannot tell how things are going to unfold." Responses to these items correlated positively, $r(91)=.47, p<.0005$.

\subsubsection{Event characteristics scales}

Nostalgia was assessed with two items: "makes me feel nostalgic" and "is a nostalgic experience for me." Responses to these items correlated positively, $r(91)=.93, p<.0005$. Purpose in Life was assessed with two items: "makes me feel life is meaningful" and "makes me feel life has a purpose". Responses to these items correlated positively, $r(91)=.79, p<.0005$. Self-Esteem was assessed with two items: "makes me like myself better" and "makes me feel good about myself." Responses to these items correlated positively, $r(91)=.71, p<.0005$. Self-Continuity was assessed with two items: "makes me feel connected with who I was in the past" and "makes me feel connected with my past." Responses to these items correlated positively, $r(91)=.85, p<$ .0005. Interpersonal Connectedness was assessed with two items: "makes me feel I can trust others" and "makes me feel connected to loved ones." Responses to these items correlated positively, $r(91)=.54, p<.0005$. Overall Rehearsal Frequency was assessed with one item: "How often have you rehearsed or reviewed this event since it occurred?" (never $=1$ to $6=$ very frequently). Finally, Event Affect was assessed with two items: "When it happened, how pleasant did this event make you feel?" and "When you remember the event now, how pleasant does the event make you feel?" (not at all $=1$ to $6=$ exceptionally). Responses to these items correlated positively, $r(86)=.32, p<.005$.

\subsection{Results and discussion}

Participants tended to recall and rate positive events from their lives that were, on average, 6.79 years old $(S D=7.24)$. This approach differs from our initial studies because in the present study we did not constrain positive event age to one week. Nevertheless, event age was uncorrelated with each of the three scales of positive mindfulness. As in all of the previous studies, the composite averages each correlated positively with each other: Focused Attention with Novelty Appreciation, $r(91)=.33, p=.002$; Focused Attention with Open-Ended Expectations, $r(91)=.21$, $p=.04$; and, Novelty Appreciation with Open-Ended Expectations, $r(91)=.36, p=.001$.

Only Focused Attention correlated positively with event-related affect, specifically with the affect prompted at recall, $r(86)=.35, p<.0005$; and, none correlated with affect felt at an event's occurrence. Further, only Focused Attention correlated positively with overall rehearsal frequency, $r(90)=.21, p=.04$. Next, Novelty Appreciation correlated positively with selfesteem, $r(91)=.46, p<.0005$. Both Focused Attention and Novelty Appreciation correlated positively with interpersonal connectedness, $r(91)=.25, p=.02$, and $r(91)=.33, p=.002$, respectively. Finally, Focused Attention, Novelty Appreciation, and Open-Ended Expectations 
each correlated positively with purpose in life, $r(91)=.33, p=.002 ; r(91)=.39, p<.0005$; and, $r(91)=.34, p=.001$, respectively. Finally, none of the dimensions of positive mindfulness correlated with nostalgia or self-continuity.

These findings add to the convergent validity of positive mindfulness. First, in Studies 1 and 2 we examined the relations between our scales and a variety of existing individual difference measures, whereas in Study 3 we examined the relations between our scales and conceptually related ratings about positive autobiographical events. Despite this difference in scope, the fact that all positive event characteristics did not correlate positively with all of our scales suggests that each of the dimensions represents a related but distinct facet of positive mindfulness.

Second, up to this study we had prompted participants each for a single positive event that was constrained temporally to within the past week, a relatively recent event. In the present study we widened the scope of positive events by prompting not only two of such events per person but also placed no temporal constraints on their recollection task. Despite these differences in approach, results across each of the studies produced a converging pattern of correlations.

Third, the validity estimates garnered in the present study support our notion that positive mindfulness is relevant to the study of a range of memorial and emotional phenomena. When thinking about their positive experiences our participants' ratings evidenced a positive correlation between Focused Attention and pleasant affect, event rehearsal frequency, and interpersonal connectedness; thus, this dimension of positive mindfulness is relevant to several domains of experience: emotional, cognitive, and social, respectively.

Further, only Novelty Appreciation correlated positively with the self-esteem boosting quality of recalling past positive experiences. Such reminiscence may make a person feel good about the self, which in turn may stimulate curiosity and an explorative use of attention, resulting in an appreciation for novelty. Such a finding is consistent with the broaden-andbuild framework of emotion regulation (Fredrickson et al., 2008).

Finally, all three of our scales correlated positively with a sense of meaning to life that thinking about past positive experiences can provide; consistent with findings from nostalgia research (Routledge et al., 2011). Indeed, reflecting on past positive events may prompt a person to reflect on the meaning and purpose of their own lives. The data suggest that doing so might actually prevent goal-oriented, future thinking, forecasting, and planning. One can experience a sense that one's expectations can, for a moment, be suspended, as reliving a positive experience by itself imbues the self with a sense of existential meaning.

Interestingly, none of our scales of positive mindfulness correlated with nostalgia or selfcontinuity. One reason for this might be that nostalgia, while a predominantly positive emotion, is sometimes bittersweet (Hepper et al., 2011). When we had asked participants to reflect on purely positive events, nostalgia may not have been as dominant a feature as it could have been. Prompting nostalgic events or events associated with mixed feelings might provoke positive mindfulness. This is an empirical issue for future research.

So far, our data support Langer's theory of mindfulness in the context of recalled positive experiences. In fact, the theory offers more dimensions than were needed to model positive experiences in our samples. Theory predicted five dimensions; however, our data suggested that only three dimensions were necessary. Across multiple samples our three-factor model fit the data better than a one-factor model, which distinguishes positive mindfulness from the onefactor trait models. To garner more validation evidence for our model, we next turned away 
from subjective self-reports of autobiographical accounts to present-oriented, experimental manipulations.

\section{Study 4}

We conducted two experiments to garner evidence for the criterion validity of positive mindfulness. In parallel we aimed to strengthen the argument that our measurement model is sensitive to fluctuations of state mindfulness, particularly with regard to experiential positivity. Hence, we manipulated theory-relevant contextual elements within a controlled setting and then assessed the degree to which these manipulations influenced participant ratings on our 9item instrument (Experiment 1), and on a single item from each of the three dimensions of our instrument (Experiment 2). To minimize mono-operational bias in evaluating the construct validity of positive mindfulness (Cook \& Campbell, 1979), the experimental tasks in both experiments were affectively neutral and relatively mundane compared to the recalled recent positive experiences we used in prior studies. To minimize mono-method bias in evaluating the construct validity of positive mindfulness (Cook \& Campbell, 1979), Experiment 1 was designed to decrease positive mindfulness; Experiment 2 was designed to increase it.

\subsection{Experiment 1}

In Experiment 1, we aimed to induce boredom in participants via a repetitive task that has been shown to provoke boredom in the laboratory (Van Tilburg \& Igou, 2011). We reasoned that because the nature of the boredom task is inherently unpleasant, any or all of our three positive mindfulness dimensions might evidence lower scores during boredom. Participants who experience only mild boredom, compared to those who experience greater boredom, may a) appreciate the novelty of the task to a greater degree, b) more strongly focus on the present, and c) formulate fewer expectations about what is going to happen in the near future. Therefore, we hypothesized that participants in the high boredom condition would score lower than participants in the low boredom condition on one or more of our subscales of positive mindfulness.

\subsubsection{Method}

\subsubsection{Participants and procedure}

Participants included 34 women and 12 men enrolled in an undergraduate psychology course at the University of Limerick. The mean sample age was 18.78 years $(S D=2.19$, range $=17-27)$. Each participant was randomly assigned to a Low Boredom condition $(n=24)$ or to a High Boredom condition $(n=22)$. Participants in the former transcribed via typing two Wikipedia entries from a web site into a text editor; participants in the latter group did the same task for 10 entries (Van Tilburg \& Igou, 2011). They next each rated an item on their level of state boredom: "To what extent did the task you just completed make you feel bored?" $(1=$ not at all to 7 = very $m u c h$ ). Following this, they completed the 9-item Positive State Mindfulness Scale (see Appendix A).

\subsubsection{Results and discussion}

The state boredom manipulation proved successful: participants in the Low Boredom condition scored significantly lower $(M=3.79, S D=1.84)$ on the boredom index than those in the High Boredom condition $(M=4.91, S D=1.57), t(44)=-2.20, p<.05$. Next, as hypothesized, participants in the Low Boredom condition evidenced higher Novelty Appreciation ratings (LS 
Mean $=4.81, S E=0.23)$ than those in the High Boredom condition (LS Mean = 4.07, $S E=0.26)$, controlling for state boredom, $F(1,38)=4.57, p<.05$, partial $\varepsilon^{2}=.11$, model $R^{2}=.14$. Further, the effect of boredom on Novelty Appreciation remained significant, controlling for state boredom and with both Focused Attention and Open-Ended Expectations entered as covariates (due to the correlations between these ratings and the outcome rating), such that participants in the Low Boredom condition evidenced higher Novelty Appreciation ratings ( $L S$ Mean $=4.81, S E=$ 0.17) than those in the High Boredom condition ( $L S$ Mean $=4.15, S E=0.19), F(1,36)=6.93, p=$ .01 , partial $\varepsilon^{2}=.16$, model $R^{2}=.64$. Although the means were in the same direction as above, Focused Attention and Open-Ended Expectations did not reach significance between boredom conditions.

In sum, participants who engaged in the more repetitive and boring task of text transcription of web site passages into a text editor had a more difficult time maintaining a sense of Novelty Appreciation than those who engaged in a similar but less repetitive task. This makes sense, because what likely seemed novel at first to those in the High Boredom condition became routine and a bigger challenge to appreciate compared to the Low Boredom condition. Such a finding suggests that the more repetitive, unchallenging and boring a task becomes the harder it was for many individuals to find and appreciate novelty in the moment. Indeed, the more mindless a task becomes to a person the less mindful they will remain during the task, in general (Csikszentmihalyi, 1975). These data show that increased boredom diminished positive mindfulness, especially the appreciation of novelty.

\subsection{Experiment 2}

Experiment 2 differed from the previous experiment in two ways. First, in Experiment 2 we sought to engage participants' attention in a task in order to increase positive mindfulness rather than decrease it. Second, as our outcome measures we assessed each dimension of positive mindfulness using only a subset of items from the full measurement instrument used in Experiment 1. Specifically, we chose the item with the highest CFA factor loading for each subscale in our earlier studies, to represent the dimensions of Novelty Appreciation, Focused Attention, and Open-Ended Expectations. Paralleling Experiment 1, we reasoned that engaging in a pleasant task that afforded the opportunity to experience positive mindfulness would boost levels of one or more of our three dimensions, compared to engaging in the same task but with less opportunity to experience positive mindfulness.

Participants in each of two conditions first read the same riddle, and were then asked to solve the riddle (see Appendix B). Participants in the Delayed Answer condition were not told the correct response before prompted to solve it; whereas participants in the Immediate Answer condition were told the correct response before prompted to solve it. The former condition contained each of the three elements of positive mindfulness. For instance, being a mildly pleasant task, a) the novelty of the riddle was there to appreciate (it was unfamiliar to most participants), b) focused attention to the present was possible because they were given the goal to solve the riddle, and c) open-ended expectation was possible because they were informed that they would learn the correct response in a few minutes.

In contrast, we reasoned that spoiling the mystery immediately by telling participants the correct response before prompting them for their response would not only stifle the opportunity to appreciate novelty, but would also shift these participants' attention away from the present (toward the future, end of the study) and lead to closed-expectations (i.e., knowing the answer eliminated the suspense of discovering the correct response). Thus, the Delayed Answer participants, compared to the Immediate Answer participants, were expected to find 
an opportunity to appreciate the novelty of the task, sustain their focus to the present, and suspend their expectations about what should or could happen in the near future as they waited for the riddle's outcome. In sum, we hypothesized that the Delayed Answer condition would produce higher scores on measures of positive mindfulness than would the Immediate Answer condition.

\subsubsection{Method}

\subsubsection{Participants and procedure}

Participants included 92 individuals (52 women, 36 men and 4 who did not specify their gender) who were enrolled in graduate programs at the University of Limerick. The mean sample age was 29.09 years $(S D=8.32$, range $=22-60)$.

Participants first read and then gave their informed consent to participate in a study entitled "What it's like when you pay attention". Each participant was randomly assigned to either the Immediate Answer condition $(n=51)$, who read a brief riddle ${ }^{1}$ and was immediately told the answer to it, or to the Delayed Answer condition $(n=41)$, who read the same riddle, then were prompted to solve it by typing a response, and later shown the correct response. Following the riddle, participants in both conditions indicated their familiarity with the riddle $(0=n o ; 1=n o$, but it seemed familiar; $2=$ yes), and then rated the extent to which they were certain they knew the correct response $(1=$ not at all certain, $2=$ a little certain, $3=$ moderately certain, $4=$ certain).

Following these ratings, both conditions completed a selection of three items from each of the three positive mindfulness subscales, one item from Focused Attention, Open-Ended Expectations and Novelty Appreciation, respectively: "At the moment my attention is absorbed in the moment", "Right now I cannot tell how things are going to unfold", and "At the moment I take great pleasure in experiencing new things" $(6=$ strongly agree, $5=$ moderately agree, $4=$ agree a little, 3 = disagree a little, 2 = moderately disagree, $1=$ strongly disagree).

Participants then reported their gender and age. On the penultimate page, those in the Delayed Answer condition were then shown the correct response to the riddle; those in the Immediate Answer condition were reminded of the correct response, which they had seen earlier. Finally, students were debriefed and thanked for their participation.

\subsubsection{Results and discussion}

The riddle manipulation proved successful: the participants who were told the answer before reading the riddle (Immediate Answer) more frequently solved the riddle correctly (40) than incorrectly (11) and those who were not told the answer before reading the riddle (Delayed Answer) more often responded incorrectly (24) than correctly (17), $\chi^{2}(1, N=92)=13.18, p<$ .0001 , Cramer's $V=.38, p<.0001$. As expected, participants in the Delayed Answer condition evidenced higher Focused Attention ratings ( $L S$ Mean $=4.66, S E=0.18$ ) than those in the Immediate Answer condition ( $L S$ Mean $=4.14, S E=0.16), F(1,90)=4.51, p<.05$, partial $\varepsilon^{2}=.05$, model $R^{2}=.05$.

This effect also occurred after controlling for the main effects of whether or not participants solved the riddle correctly, whether they had heard the riddle before the experiment, the extent to which they were certain that they knew the outcome, and with ratings of Novelty Appreciation and Open-Ended Expectations included as covariates (due to the correlations between these ratings and the outcome rating). Under these controlled conditions, Focused Attention ratings were higher for those in the Delayed Answer condition (LS Mean $=4.55, S E=$ 
$0.17)$ than those in the Immediate Answer condition ( $L S$ Mean $=3.98, S E=0.19), F(1,80)=5.11, p$ $<.05$, partial $\varepsilon^{2}=.06$, model $R^{2}=.47$.

Participants in the Immediate Answer condition evidenced a larger Open-Ended Expectation mean $(L S$ Mean $=4.94, S E=0.25)$ than those in the Delayed Answer condition ( $L S$ Mean $=4.35, S E=0.21$ ), however, this difference was statistically non-significant, $F(1,83)=3.30$, $p=.07$. Finally, participants in the Immediate Answer condition evidenced nearly identical Novelty Appreciation means ( $L S$ Mean $=4.41, S E=0.23$ ) to those in the Delayed Answer condition (LS Mean $=4.48, S E=0.20), F(1,83)<1$, ns.

These results suggest that the participants who learned the riddle's outcome immediately allowed their present focus of attention to wander more than those who had to wait to learn the riddle's outcome. Those in the delayed answer condition had a legitimate reason to sustain their attention to the present moment. Such a result supports our hypothesis that attentional engagement increases positive mindfulness.

\section{General discussion}

The present research makes several important contributions to the field of positive psychology. First, our data clearly demonstrate that reported states of mindfulness during positive experiences are multidimensional (see Baer et al., 2006). Although social cognitive theorizing (Langer, 1992, 1997) strongly supports a multifaceted conceptualization of mindfulness, existing measures of this construct exclusively provide only a unidimensional total score. Further, existing measures of mindfulness focus on disposition and trait, whereas we posit and supported a state, positive state mindfulness.

Across four independent samples, our data unequivocally demonstrate that a theorygrounded three-factor model (Focused Attention, Novelty Appreciation, Open-Ended Expectations) provided an appropriate and generalizable model for assessing states of positive mindfulness, whereas a one-factor model did not. Thus, our data strongly confirm a priori, the multidimensionality of mindfulness, and they support the conclusion that states of positive mindfulness are meaningfully conceptualized in terms of focused attention, appreciation of novel stimuli, and open-ended expectations in relation to an unfolding experience.

As a second important contribution to the literature, our multidimensional instrument is a valuable measurement tool for researchers who wish to operationalize mindfulness as a multifaceted state construct. Indeed, doing so is consistent with existing theoretical frameworks. The data from Study 1 demonstrate clearly the structural validity and ability of our three-factor model to replicate positive state mindfulness. Across a combined sample of 1,363 respondents, the three-factor measurement model not only provided an acceptable psychometric representation of responses to the set of nine self-report items, but also consistently fit the data significantly better than a unitary, one-factor model and yielded brief subscales that had reasonable reliabilities.

Providing a third valuable contribution, the data from Study 2 supported the construct validity of our three-factor model of positive mindfulness. In support of discriminant validity, each of the three positive mindfulness subscales correlated differently with the set of criterion measures. When controlling for differences in reliability, the three subscales were differentially inter-correlated, such that Focused Attention was equally related to both Novelty Appreciation and Open-Ended Expectations, Novelty Appreciation was more strongly related to Focused Attention than to Open-Ended Expectations, and Open-Ended Expectations was more strongly related to Focused Attention than to Novelty Appreciation. This pattern of results supports the 
conclusion that positive mindfulness is multidimensional, and that these three underlying dimensions are related but distinct.

As a fourth contribution to the literature, our data support the conclusion that specific states of positive mindfulness are conceptually distinct from both general trait mindfulness and general trait mindlessness (see Sternberg, 2000). In Study 2 (Table 4), including trait measures of both mindfulness (MMS) and mindlessness (MAAS) enabled us to demonstrate that: a) trait mindfulness and trait mindlessness share only about $6 \%$ of their variance $(r=.25)$; b) traits of high mindfulness and low mindlessness are more strongly associated with individual differences in need for cognition, absorption, uncertainty tolerance, and need for structure than are states of positive mindfulness; c) high trait mindfulness (MMS total score) predisposes people toward higher levels of Novelty Appreciation and Open-Ended Expectations, but is unrelated to Focused Attention during positive experiences; and, d) high trait mindlessness (MAAS total score) predisposes people toward Open-Ended Expectations during positive experiences. This last finding is important because it illustrates a specific way in which trait mindlessness is distinct from the absence of mindfulness-being characteristically mindless may actually help people avoid closing their minds to future possibilities while positive experiences are unfolding.

Confirming specific nomological hypotheses about convergent and discriminant validity, the subscales of Focused Attention and Novelty Appreciation demonstrated reliable associations with self-assessed capacities to savor positive experiences prospectively (by anticipating), concurrently (by savoring the moment), and retrospectively (by reminiscing), and with tolerance for uncertainty. Further confirming our hypotheses, responses to Focused Attention correlated positively with trait absorption, but were unrelated to the need for structure; and all three positive mindfulness subscales were unrelated to the need for cognition.

Yet our data are not entirely consistent with a priori predictions. Somewhat unexpectedly, Open-Ended Expectations were unrelated to self-assessed capacity to savor prospectively and concurrently, and were negatively correlated with perceived capacity to savor retrospectively. Consistent with past theorizing (Bryant \& Veroff, 2007), we suggest that savoring is most strongly associated with focused attention on pleasurable stimuli, and that the tendency to savor through reminiscence may predispose individuals to restrict expectations during ongoing positive experiences, in order to facilitate encoding of memories for later recall. Also inconsistent with hypotheses, Open-Ended Expectations were unrelated to uncertainty tolerance, and Novelty Appreciation was unrelated to trait absorption. Nevertheless, the overall pattern of correlations of the three positive state mindfulness subscales with the set of criterion measures supported the convergent and discriminant validity of our multidimensional model of positive mindfulness.

Despite these conceptual and psychometric contributions, the present research is not without its limitations. The types of experiences that we sampled represent emotionally pleasant but relatively mundane and ordinary recent experiences. We did not intend to sample respondents' self-reported peak experiences, such as memories associated with intense levels of positive emotional arousal. We acknowledge, however, that some individuals did report such events, and these events were inter-mixed with the ordinary pleasant events. Perhaps other dimensions of mindfulness that we initially posited (e.g., Categorization and DistinctionMaking) would have emerged had we examined a wider range of positive experiences.

In addition, although we included large samples of respondents, they were predominantly undergraduate students (an exception was Study 4, Experiment 2). Although we see no theoretical reason to believe college students' states of positive mindfulness should differ from 
those of older adults, it remains important to demonstrate that our multidimensional measure of positive mindfulness generalizes to a wider community population.

Furthermore, Studies 1, 2 and 3 assessed states of positive mindfulness retrospectively by asking respondents to report what they remembered experiencing during a recent positive event. Although we minimized the potentially distorting effects of the passage of time by restricting respondents to a positive experience that occurred during the past week (Studies 12 ), we have no way of validating the accuracy of these retrospective self-reports. While it would be advantageous in some respects to assess mindfulness concurrently during ongoing positive events (i.e., experience sampling methodology), doing so might well alter the very states that participants are experiencing. Nonetheless, experience sampling methods could assist in validating positive state mindfulness.

In Study 4 we manipulated state boredom and task engagement. Both experiments added to the validity of positive mindfulness using our scale. Indeed, Experiment 1 supported the notion that a repetitive and boring task impacted on positive mindfulness negatively, particularly affecting appreciation for novelty. Experiment 2 supported the notion that limited engagement with a simple cognitive task interfered with a person's ability to focus their attention on the present. Stated differently, giving people the opportunity to engage in a puzzling task prompted them to focus their attention longer throughout the experiment, compared to those whose opportunity to engage was limited. These findings support the criterion validity of our multidimensional measure of positive state mindfulness.

We hope that researchers seek to identify specific characteristics of positive events that promote states of positive mindfulness. For example, situational elements of uncertainty, spontaneity, novelty, complexity, surprise, inspiration, awe, nostalgia, and the absence of distraction may enhance the tendency to be mindful as positive experiences are unfolding (Bryant \& Veroff, 2007). It would be valuable to manipulate such characteristics experimentally and measure participants' responses using our states of positive mindfulness subscales.

Related to the applications of savoring (Bryant \& Veroff, 2007), we believe there are numerous applications of positive state mindfulness. We began by modeling spontaneous positive mindfulness in ordinary positive experience. Our data suggest that even a simple reminder about recent positive past events can rekindle positive mindfulness. We speculate that our dimensions of positive state mindfulness will be useful for practitioners of many disciplines. Indeed, increasing positive state mindfulness bolsters daily enjoyment.

For example, in education our measure will help educators examine students' engagement with novel information, and will help elucidate why some students lose interest in a subject while others retain their interest. Learning requires considerable effort; the expenditure of such effort can be a source of enjoyment and personal meaning. We think that assessing positive state mindfulness in the classroom will offer insights about the learning process, and ultimately assist educators to improve the quality of their instruction, as well as their students' learning satisfaction and performance.

As wellbeing researchers, we focus on the psychological processes that maintain health. Positive state mindfulness offers new possibilities for understanding the construction and maintenance of wellbeing; at the same time, we believe that it also offers new possibilities to understand what happens when wellbeing is disrupted and subdued. For example, clinicians and counselors benefit from assessing not only their clients' maladaptive symptoms, such as anhedonia and rumination, but also benefit from assessing the lack of their clients' adaptive indicators, such an appreciation for novelty in the present moment. We view the goals to increase positive mindfulness and savoring as facilitative with mindfulness-based programs 
(e.g., stress management, dialectical behavioral therapy). Such goals include intrapersonal and interpersonal processes. In sum, we hope that positive state mindfulness and our measure will assist professionals in their efforts to improve the quality of life of those for whom they care.

\section{Acknowledgements}

We would like to thank Ellen Langer, Todd Bodner, and Claudia Dalbert for sharing their measures with us. We are grateful to Shannon Archuleta, Adam DeHoek, Carrie Ericksen, Scott King, Oisín Ryan, Colette Smart, and Wijnand Van Tilburg for their efforts in data collection, coding and entry, and to Elaine L. Kinsella, Brent D. Robbins, and Sarah E. Wood for their comments on earlier drafts of this manuscript.

\section{Authors}

Timothy D. Ritchie

University of Limerick

tim.ritchie@ul.ie

Fred B. Bryant

Loyola University

\section{Publishing Timeline}

Received 14 April 2012

Accepted 9 July 2012

Published 29 August 2012

\section{References}

Baer, R. A., Smith, G. T., \& Allen, K. B. (2004). Assessment of mindfulness by self-report: The Kentucky inventory of mindfulness skills. Assessment, 11, 191-206. http://dx.doi.org/10.1177/1073191104268029

Baer, R. A., Smith, G. T., Hopkins, J., Krietemeyer, J., \& Toney, L. (2006). Using self-report assessment methods to explore facets of mindfulness. Assessment, 13, 27-45. http://dx.doi.org/10.1177/1073191105283504

Bentler, P. M., \& Bonett, D. G. (1980). Significance tests and goodness-of-fit in the analysis of covariance structures. Psychological Bulletin, 88, 588-606. http://dx.doi.org/10.1037/0033-2909.88.3.588

Bishop, S. R., Lau, M., Shapiro, S., Carlson, L., Carmody, J., Segal, Z. V., Abbey, S., Speca, M., Velting, D., \& Devins, G. (2004). Mindfulness: A proposed operational definition. Clinical Psychology: Science and Practice, 11, 230-241. http://dx.doi.org/10.1093/clipsy.bph077

Bodner, T. E., \& Langer, E. J. (2001). Individual differences in mindfulness: The Mindfulness/Mindlessness Scale. Poster presented at the $13^{\text {th }}$ annual American Psychological Society Convention, Toronto, Ontario, Canada.

Bollen, K. A. (1989). Structural equations with latent variables. New York: Wiley.

Brown, J., \& Langer, E. (1990). Mindfulness and intelligence: A comparison. Educational Psychologist, 25, 305-335.

Brown, K. W., \& Ryan, R. M. (2003). The benefits of being present: Mindfulness and its role in psychological well-being. Journal of Personality and Social Psychology, 84, 822-848. http://dx.doi.org/10.1037/0022-3514.84.4.822

Brown, K. W., West, A. M., Loverich, T. M., \& Biegel, G. M. (2011). Assessing adolescent mindfulness: Validation of an adapted Mindful Attention Awareness Scale in adolescent normative and psychiatric populations. Psychological Assessment, 23, 1023-1033. http://dx.doi.org/10.1037/a0021338

Browne, M. W., \& Cudeck, R. (1993). Alternative ways of assessing model fit. In K. A. Bollen \& J. S. Long (Eds.), Testing structural equation models (pp. 136-162). Newbury Park, CA: Sage. 
Bryant, F. B. (1989). A four-factor model of perceived control: Avoiding, coping, obtaining, and savoring. Journal of Personality, 57, 773-797. http://dx.doi.org/10.1111/j.1467-6494.1989.tb00494.x

Bryant, F. B. (2000). Assessing the validity of measurement. In L. G. Grimm \& P. R. Yarnold (Eds.), Reading and understanding more multivariate statistics (pp. 99-146). Washington, DC: American Psychological Association.

Bryant, F. B. (2003). Savoring Beliefs Inventory (SBI): A scale for measuring beliefs about savoring. Journal of Mental Health, 12, 175-196. http://dx.doi.org/10.1080/0963823031000103489

Bryant, F. B., \& Veroff, J. (2007). Savoring: A new model of positive experience. Mahwah, NJ: Lawrence Erlbaum Associates.

Bryant, F. B., King, S. P., \& Smart, C. M. (2006). Multivariate statistical strategies for construct validation in positive psychology. In A. G. Ong \& M. Van Dulmen (Eds.), Oxford handbook of methods in positive psychology (pp. 61-82). New York: Oxford University Press.

Buchheld, N., Grossman, P., \& Walach, H. (2001). Measuring mindfulness in insight meditation Vipassana and meditation-based psychotherapy: The development of the Freiburg Mindfulness Inventory (FMI). Journal of Meditation and Meditation Research, 1, 11-34.

Cacioppo, J. T., \& Petty, R. E. (1982). The need for cognition. Journal of Personality and Social Psychology, 42, 116-131. http://dx.doi.org/10.1037/0022-3514.42.1.116

Carson, S. H., \& Langer, E. J. (2006). Mindfulness and self-acceptance. Journal of Rational-Emotive $\mathcal{E}$ Cognitive-Behavior Therapy, 24, 29-43. http://dx.doi.org/10.1007/s10942-006-0022-5

Chaiken, S., \& Trope, Y. (1999). Dual-process theories in social psychology. New York, NY: The Guilford Press.

Chiesa, A. \& Malinowski, P. (2011). Mindfulness-based approaches: Are they all the same? Journal of Clinical Psychology, 67, 404-424. http://dx.doi.org/10.1002/jclp.20776

Cook, T. D., \& Campbell, D. T. (1979). Quasi-experimentation: Design and analysis issues for field settings. Chicago, IL: Rand McNally.

Csikszentmihalyi, M. (1975). Beyond boredom and anxiety: Experiencing flow in work and play. San Francisco, CA: Jossey-Bass.

Dalbert, C. (1999). Die ungewissheitstoleranzskala: Skaleneigenschaften und validierungsbefunde [The Uncertainty Tolerance Scale: Reliability and validation]. Hallesche Berichte zur Pädagogischen Psychologie, 1, Halle, Germany.

DeVellis, R. F. (1991). Scale development: Theory and application. Newbury Park, CA: Sage.

Erisman, S. M., \& Roemer, L. (2010). A preliminary investigation of the effects of experimentally induced mindfulness on emotional responding to flip clips. Emotion, 10, 72-82. http://dx.doi.org/10.1037/a0017162

Farb, N. A. S., Segal, Z. V., Mayberg, H., Bean, J. McKeon, D., Fatima, Z., \& Anderson, A. K. (2007). Attending to the present: Mindfulness meditation reveal distinct neural modes of self reference. Social Cognitive and Affective Neuroscience, 2, 313-322. http://dx.doi.org/10.1093/scan/nsm030

Feldman, G., Hayes, A., Kumar, S., Greeson, J., \& Laurenceau, J. (2007). Mindfulness and emotion regulation: The development and initial validation of the Cognitive and Affective Mindfulness Scale-Revised (CAMS-R). Journal of Psychopathology and Behavioral Assessment,29, 177-190. http://dx.doi.org/10.1007/s10862-006-9035-8

Fredrickson, B. L., Cohn, M. A., Coffey, K. A., Pek, J., \& Finkel, S. M. (2008). Open hearts build lives: Positive emotions, induced through loving-kindness mediation, build consequential personal resources. Journal of Personality and Social Psychology, 95, 1045-1062. http://dx.doi.org/10.1037/a0013262

Haigh, E. A. P., Moore, M. T., Kashdan, T. B., \& Fresco, D. M. (2011). Examination of the factor structure and concurrent validity of the Langer Mindfulness/Mindlessness Scale. Assessment, 18, 11-26. http://dx.doi.org/10.1177/1073191110386342

Hepper, E. G., Ritchie, T. D., Sedikides, C., \& Wildschut, T. (2012). Odyssey's end: Lay conceptions of nostalgia reflect its original homeric meaning. Emotion, 12, 102-119.

http://dx.doi.org/10.1037/a0025167 
Höfling, V., Moosbrugger, H., Schermelleh-Engel, K., \& Heidenreich, T. (2011). Mindfulness of mindlessness? A modified version of the Mindful Attention and Awareness Scale (MAAS). European Journal of Psychological Assessment, 27, 59-64. http://dx.doi.org/10.1027/1015-5759/a000045

Hu, L., \& Bentler, P. M. (1998). Fit indices in covariance structure modeling: Sensitivity to underparameterized model misspecification. Psychological Methods, 3, 424-453. http://dx.doi.org/10.1037/1082-989X.3.4.424

Jacob, J. C., \& Brinkerhoff, M. B. (1999). Mindfulness and subjective well-being in the sustainability movement: A further elaboration of multiple discrepancies theory. Social Indicators Research, 46, 341368. http://dx.doi.org/10.1023/A:1006941403481

Johnson, B. T. (1995). D-Stat: Software for the meta-analytic review of research literature (Version 1.11). Hillsdale, NJ: Erlbaum.

Jöreskog, K. G. (1993). Testing structural equation models. In K. A Bollen \& J. S. Long (Eds.), Testing structural equation models (pp. 294-316). Newbury Park, CA: Sage.

Jöreskog, K., \& Sörbom, D. (1996). LISREL 8: User's reference guide. Chicago, IL: Scientific Software International, Inc.

Kabat-Zinn, J. (2005). Coming to our senses: Healing ourselves and the world through mindfulness. New York, NY: Hyperion.

Langer, E. J. (1992). Matters of mind: Mindfulness/mindlessness in perspective. Consciousness and Cognition, 1, 289-305. http://dx.doi.org/10.1016/1053-8100(92)90066-J

Langer, E. J. (1997). The power of mindful learning. Reading, MA: Addison-Wesley Publishing Company, Inc.

Langer, E. J., \& Moldoveanu, M. (2000). The construct of mindfulness. Journal of Social Issues, 56, 1-10. http://dx.doi.org/10.1111/0022-4537.00148

Langer, E. J., Bashner, R., \& Chanowitz, B. (1985). Decreasing prejudice by increasing discrimination. Journal of Personality and Social Psychology, 49, 113-120. http://dx.doi.org/10.1037/0022-3514.49.1.113

Langer, E. J., Hatem, M., Joss, J., \& Howell, M. (1989). Conditional teaching and mindful learning: The role of uncertainty in education. Creativity Research Journal, 2, 139-150.

http://dx.doi.org/10.1080/10400418909534311

Lau, M. A., Bishop, S. R., Segal, Z.V., Buis, T., Anderson, N. D., Carlson, L., \& Devins, G. (2006). The Toronto mindfulness scale: Development and validation. Journal of Clinical Psychology, 62, 1445-1467. http://dx.doi.org/10.1002/jclp.20326

Neuberg, S. L. \& Newsome, J. T. (1993). Personal need for structure: Individual differences in the desire for simple structure. Journal of Personality and Social Psychology, 65, 113-131. http://dx.doi.org/10.1037/0022-3514.65.1.113

Ritchie, T. D., Skowronski, J. J., Hartnett, J. L., Wells, B. M., \& Walker, W. R. (2009). The fading affect bias in the context of emotion activation level, mood, and personal theories of emotion change. Memory, 17, 428-444. http://dx.doi.org/10.1080/09658210902791665

Ritchie, T. D., Skowronski, J. J., Wood, S. E., Walker, W. R., Vogl, R. J., \& Gibbons, J. A. (2006). Event selfimportance, event rehearsal, and the fading affect bias in autobiographical memory. Self and Identity, 5, 172-195. http://dx.doi.org/10.1080/15298860600591222

Rothwell, N. (2006). The different facets of mindfulness. Journal of Rational-Emotive and Cognitive-Behavior Therapy, 24, 79-86. http://dx.doi.org/10.1007/s10942-006-0023-4

Routledge, C., Arndt, J., Wildschut, T., Sedikides, C., Hart, C., Juhl, J., Vingerhoets, A. J. J. M., \& Schlotz, W. (2011). The past makes the present meaningful: Nostalgia as an existential resource. Journal of Personality and Social Psychology, 101, 638-652. http://dx.doi.org/10.1037/a0024292

Sternberg, R. J. (2000). Images of mindfulness. Journal of Social Issues, 56, 11-26. http://dx.doi.org/10.1111/0022-4537.00149

Teasdale, J. D., Segal, Z. V., Williams, J. M. G., Ridgeway, V. A., Soulsby, J. M., \& Lau. M. A. (2000). Prevention of relapse/recurrence in major depression by mindfulness-based cognitive therapy. Journal of Consulting and Clinical Psychology, 68, 615-625. http://dx.doi.org/10.1037/0022-006X.68.4.615 
Tellegen, A., \& Atkinson, G. (1974). Openness to absorbing and self-altering experiences ("absorption"), a trait related to hypnotic susceptibility. Journal of Abnormal Psychology, 83, 268-277. http://dx.doi.org/10.1037/h0036681

Thompson, B. L., \& Waltz, J. (2007). Everyday mindfulness and mindfulness meditation: Overlapping construction or not? Personality and Individual Differences, 43, 1875-1885.

http://dx.doi.org/10.1016/j.paid.2007.06.017

Van Tilburg, W. A. P., \& Igou, E. R. (2011). On boredom and social identity: A pragmatic meaningregulation approach. Personality and Social Psychology Bulletin. http://dx.doi.org/10.1177/0146167211418530

Walker, W. R., Skowronski, J. J., Gibbons, J. A., Vogl, R. J., \& Ritchie, T. D. (2009). Why people rehearse their memories: Frequency of use and effects on the intensity of emotions associated with autobiographical memories. Memory, 17, 428-444. http://dx.doi.org/10.1080/09658210903107846

Wild, T. C., Kuiken, D., \& Schopflocher, D. (1995). The role of absorption in experiential involvement. Journal of Personality and Social Psychology, 69, 569-579. http://dx.doi.org/10.1037/0022-3514.69.3.569

Wildschut, T., Sedikides, C., Arndt, J., \& Routledge, C. (2006). Nostalgia: Content, triggers, functions. Journal of Personality and Social Psychology, 91, 975-993. http://dx.doi.org/10.1037/0022-3514.91.5.975

Wolff, H-G., \& Preising, K. (2005). Exploring item and higher order factor structure with the SchmidLeiman solution: Syntax codes for SPSS and SAS. Behavior Research Methods, 37, 48-58.

http://dx.doi.org/10.3758/BF03206397 


\section{Appendix A. The positive state mindfulness scale}

Permission to use. Permission for use of the Positive State Mindfulness Scale (PSMS) is not necessary when use is for academic research or educational purposes. Reference the authors by citing the present article. Use of the PSMS in profit-making ventures requires permission and a nominal charge. Inclusion of the PSMS within a larger scale that will be copyrighted also requires permission. Send a request to the first author.

Usage and scoring. We staggered the item presentation order; a Focused Attention item, followed by a Novelty Appreciation item, followed by an Open-Ended Expectation item, and so $\mathrm{on}$. We set each item to a 6 -point scale $(1=$ strongly disagree, $2=$ disagree, $3=$ disagree somewhat, $4=$ agree somewhat, $5=$ agree, and $6=$ strongly agree). Score each subscale by computing either the average or the sum. Each subscale is grouped below.

Instructions. Phrase each item to fit your research question and design. For instance, in Studies 1-3 we assessed recalled positive events; hence, our instructions were phrased in the past tense: "Recall a recent positive experience that occurred sometime within the past five days." In Study 4, we assessed positive state mindfulness following different experimental manipulations; hence, we phrased the items in the present tense.

\begin{tabular}{|c|c|c|}
\hline Dimension & Past Tense & Present Tense \\
\hline \multirow[t]{2}{*}{$\begin{array}{l}\text { Focused } \\
\text { Attention }\end{array}$} & $\begin{array}{l}\text { During my positive experience my } \\
\text { attention was focused on what was } \\
\text { happening just then. }\end{array}$ & $\begin{array}{l}\text { My attention is focused on what } \\
\text { is happening right now. }\end{array}$ \\
\hline & $\begin{array}{l}\text {...my attention was absorbed in the } \\
\text { moment. } \\
\text {...I was aware of nothing else except } \\
\text { what I was going through right then. }\end{array}$ & $\begin{array}{l}\text { My attention is absorbed in the } \\
\text { moment. } \\
\text { I am aware of nothing else } \\
\text { except what I am going though } \\
\text { right now. }\end{array}$ \\
\hline \multirow[t]{3}{*}{$\begin{array}{l}\text { Novelty } \\
\text { Appreciation }\end{array}$} & $\begin{array}{l}\text { During my positive experience I enjoyed } \\
\text { the newness of the moment. }\end{array}$ & $\begin{array}{l}\text { I enjoy the newness of this } \\
\text { moment. }\end{array}$ \\
\hline & $\begin{array}{l}\text {...I took great pleasure in experiencing } \\
\text { new things. }\end{array}$ & $\begin{array}{l}\text { At the moment I take great } \\
\text { pleasure in experiencing new } \\
\text { things. }\end{array}$ \\
\hline & ...everything happening seemed unique & Right now everything \\
\hline \multirow[t]{3}{*}{$\begin{array}{l}\text { Open-Ended } \\
\text { Expectations }\end{array}$} & $\begin{array}{l}\text { to me. } \\
\text { During my positive experience I wasn't } \\
\text { sure of what to expect. }\end{array}$ & $\begin{array}{l}\text { happening seems unique to me. } \\
\text { Right now I am not sure what to } \\
\text { expect. }\end{array}$ \\
\hline & $\begin{array}{l}\text {...I couldn't tell how things were going } \\
\text { to unfold. }\end{array}$ & $\begin{array}{l}\text { Right now I cannot tell how } \\
\text { things are going to unfold. }\end{array}$ \\
\hline & $\begin{array}{l}\text {...I felt like anything could happen from } \\
\text { one moment to the next. }\end{array}$ & $\begin{array}{l}\text { I feel like anything could } \\
\text { happen from one moment to the } \\
\text { next. }\end{array}$ \\
\hline
\end{tabular}




\section{Appendix B}

The riddle used in Study 4, Experiment 2: "A boy was at a carnival and went to a booth where a man said to the boy, 'If I write your exact weight on this piece of paper then you have to give me $€ 50$, but if I cannot, I will pay you €50.' The boy looked around and saw no scale, so he agrees thinking no matter what the man writes the boy will just say that he weighs more or less. In the end the boy ended up paying the man €50. How did the man win the bet?" http://www.blurtit.com/q627108.html 